\title{
Curvature Effects on the Vibration Characteristics of Doubly Curved Shallow Shells with General Elastic Edge Restraints
}

\author{
Hui Shi, ${ }^{1}$ Teijun Yang, ${ }^{1}$ Shiliang Jiang, ${ }^{1}$ W. L. Li, ${ }^{2}$ and Zhigang Liu ${ }^{1}$ \\ ${ }^{1}$ College of Power and Energy Engineering, Harbin Engineering University, 145 Nantong Street, Harbin, Heilongjiang 150001, China \\ ${ }^{2}$ Department of Mechanical Engineering, Wayne State University, 5050 Anthony Wayne Drive, Detroit, MI 48202, USA \\ Correspondence should be addressed to Teijun Yang; yangtiejun@hrbeu.edu.cn
}

Received 25 July 2014; Revised 20 October 2014; Accepted 3 November 2014

Academic Editor: Jeong-Hoi Koo

Copyright (c) 2015 Hui Shi et al. This is an open access article distributed under the Creative Commons Attribution License, which permits unrestricted use, distribution, and reproduction in any medium, provided the original work is properly cited.

\begin{abstract}
Effects of curvature upon the vibration characteristics of doubly curved shallow shells are assessed in this paper. Boundary conditions of the shell are generally specified in terms of distributed elastic restraints along the edges. The classical homogeneous boundary supports can be easily simulated by setting the stiffnesses of restraining springs to either zero or infinite. Vibration problems of the shell are solved by a modified Fourier series method that each of the displacements is invariably expressed as a simple trigonometric series which converges uniformly and acceleratedly over the solution domain. All the unknown expansion coefficients are treated equally as a set of independent generalized coordinates and solved using the Rayleigh-Ritz technique. The current method provides a unified solution to the vibration problems of curved shallow shells involving different geometric properties and boundary conditions with no need of modifying the formulations and solution procedures. Extensive tabular and graphical results are presented to show the curvature effects on the natural frequencies of the shell with various boundary conditions.
\end{abstract}

\section{Introduction}

Vibration problems of shell structures have long been of considerable attention by the researchers and engineers because they are widely used in structural, mechanical, and aerospace engineering applications. Leissa [1] wrote a monograph about the vibration of shells and summarized approximately 1000 related publications which had been done before 1973. Earlier investigations also have been reviewed by Qatu $[2,3]$ and Liew et al. [4].

Shallow shells can be considered as plates having small curvature in two perpendicular directions. It has three familiar types, spherical (Figure 1(a)), circular cylindrical (Figure 1(b)), and hyperbolic paraboloidal (Figure 1(c)) when the Gaussian curvature $\left(1 / R_{a} R_{b}\right)$ is positive, zero, and negative. The first theoretical study on the frequency analysis of shallow cylindrical shells was reported by Palmer [5]. Using cylindrical shell element, Olson and Lindberg [6] studied the vibratory behaviors of a cantilevered curved fan blade. They also investigated the dynamic characteristics of shallow shell structures using the conforming triangular shaped shell elements $[7,8]$. Nath [9] determined the natural frequencies of a fully clamped cylindrical shell. Kantorovich's method for reducing the partial differential equations to a set of ordinary differential equations was applied by Petyt and Nath [10] to study the free vibration characteristics of a singly curved rectangular plate. Petyt [11] also collected four theoretical methods for the vibration analysis of a singly curved rectangular plate and compared numerical results with the experimental results [9]. An approximate solution for the vibration analysis of open shallow cylindrical shells was presented by Elishakoff and Wiener [12]. The doubly curved right helicoidal shell elements were used by Walker [13] to investigate curved twisted fan blades. Although the finite element method has been widely used in solving various shell vibration problems, it is sometimes less desired as compared with an analytical solution because the parameters of concern are all digitized and their significance can be easily lost in the numerical or discretization process. From practical point of view, when a shell is elastically restrained, the springs will have to be manually created in a finite element model, which can easily become an overwhelming task, especially when spring rates vary along an edge. This concern will become more remarked when a stochastic process or field will have to be taken into account. 


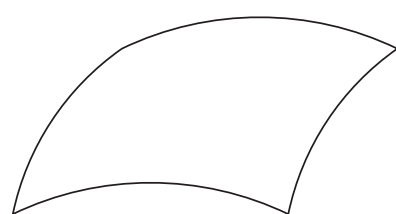

(a)

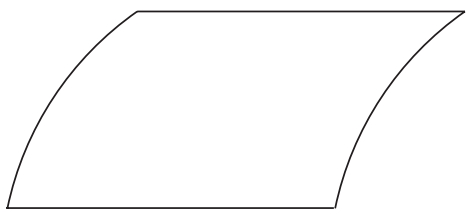

(b)

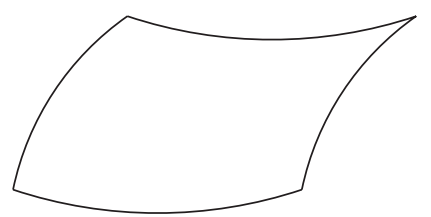

(c)

FIGURE 1: Shells of positive, zero, and negative Gaussian curvature: (a) spherical, (b) circular cylindrical, and (c) hyperbolic paraboloidal.

The Ritz method with algebraic polynomial trial functions was used by Leissa and his coworkers $[15,18,19]$ to study the vibration characteristics of different types of shallow shells with various boundary conditions. Narita and Leissa [20] studied the vibration of corner point supported shallow shells. Lee et al. [21] compared the shallow and deep shell theories using cantilevered circular cylindrical shells with rectangular planform. In $[15,18-21]$, the boundary conditions had been imposed explicitly because the built-in basic function to satisfy the kinematic shell boundaries was not specified. Qatu and Leissa [16, 22-24] also used the Ritz method based on algebraic polynomial displacement functions to investigate the effects of edge constraints on the vibrations of shallow shells.

A numerical approximation with $p b-2$ functions was employed by Liew and Lim [14, 17, 25-27] to solve vibratory behaviors of shallow shells with different complicating factors. The limits of the shallow shell theory were investigated by Liew et al. [28] using the $p$-Ritz method. It was determined that the shallow shell theory was accurate enough if the subtended angle of a shell is no more than $40^{\circ}$. Recently, the spline finite strip method [29] and differential quadrature method (DQM) [30] were used to study the vibrations of circular curved panels.

Although vibration problems of shallow shells have been extensively studied for many years, most of the existing investigations are specifically dealt with shells having particular type and classical boundary conditions, while curvature effects on the vibration characteristics of doubly curved shallow shells with general elastic boundary supports have received little attention. Vlasov [31] pointed out that shells having negative Gaussian curvature will have the lowest frequencies, but he made no further study of this problem. For a shell that has a rectangular planform supported by shear diaphragms [32], it is shown that the frequencies of all modes became larger with positively increasing values of $R_{b} / R_{a}$, whereas negatively changing values of $R_{b} / R_{a}$ cause first decreasing, then increasing frequencies. The primary objective of the present work is to assess the effects of curvature upon the natural frequencies of shallow shells with arbitrary elastic boundary conditions. For this purpose, four types of uniformly distributed elastic springs are specified along each edge to realize various boundary conditions. It represents a situation which will be much more practical in engineering applications. A modified Fourier series method in which all the displacements are expressed in the form of trigonometric functions is used in this investigation. Since the trigonometric functions are sufficient completeness and

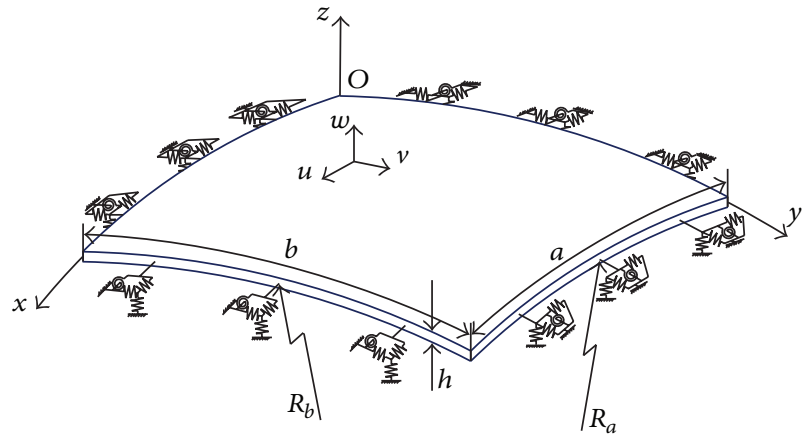

FIgURE 2: Geometrical parameters and coordinate system of a doubly curved shallow shell with elastically restrained edges.

smoothness in the solution domain, Rayleigh-Ritz method is employed here instead of solving the series coefficients which simultaneously satisfy both the governing differential equations and boundary conditions. Extensive tabular and graphical results are presented to show the effects of curvature upon the natural frequencies of shallow shells with different boundary conditions. The changing trends of the frequencies varying with the curvatures are explained in detail.

\section{Theoretical Formulations}

A doubly curved shell on rectangular planform with uniform thickness $h$ is illustrated in Figure 2. The shell is described in a curvilinear coordinate system and considered shallow for its small rise compared to the minimum radii of curvature. The curvilinear lengths of edges are denoted as $a$ and $b$ while $l_{a}$ and $l_{b}$ are the lengths of planform. $R_{a}$ and $R_{b}$ are constant principal radii of curvature in $x$ and $y$ direction, respectively. Boundary conditions of the shallow shell are specified as general elastic restraints which are described in terms of flexural, longitudinal, tangential, and rotational springs of arbitrary stiffnesses. For simplicity, it is assumed that the restraining springs have uniform stiffness distributions along each edge. All the classic homogeneous boundary conditions can be obtained by setting the stiffness coefficients equal to either zero or infinity. Other more complex boundary conditions, such as partial and nonuniform elastic supports, can be readily dealt with [33].

Vibration of the doubly curved shallow shell is considered three-dimensional: $u(x, y), v(x, y)$, and $w(x, y)$, respectively, denotes the displacement at a given point on the middle 
surface of the shell in $x, y$, and $z$ directions. The strain-displacement relationships for thin shells which are based on Love's first approximation assumptions are adopted in the present study. Strain components in an arbitrary point on the shell are defined by the relations

$$
\varepsilon_{x}=\varepsilon_{x_{0}}+z \tau_{x}, \quad \varepsilon_{y}=\varepsilon_{y_{0}}+z \tau_{y}, \quad \varepsilon_{x y}=\varepsilon_{x y_{0}}+z \tau_{x y},
$$

where $z$ is the distance of the shell from the middle surface,

$$
\varepsilon_{x_{0}}=\frac{\partial u}{\partial x}+\frac{w}{R_{a}}, \quad \varepsilon_{y_{0}}=\frac{\partial v}{\partial y}+\frac{w}{R_{b}}, \quad \varepsilon_{x y_{0}}=\frac{\partial u}{\partial y}+\frac{\partial v}{\partial x}
$$

are the middle surface strain-displacement relationships, and

$$
\tau_{x}=-\frac{\partial^{2} w}{\partial x^{2}}, \quad \tau_{y}=-\frac{\partial^{2} w}{\partial y^{2}}, \quad \tau_{x y}=-2 \frac{\partial^{2} w}{\partial x \partial y}
$$

are the changes in the curvature and torsion of the middle surface. Neglecting $\sigma_{z}$, the strain potential energy of the deformed shallow shell is given as

$$
V_{\text {sh }}=\frac{1}{2} \int_{0}^{a} \int_{0}^{b} \int_{-h / 2}^{h / 2}(\sigma \varepsilon) \times\left(\frac{R_{a}+z}{R_{a}}\right)\left(\frac{R_{b}+z}{R_{b}}\right) \mathrm{d} x \mathrm{~d} y \mathrm{~d} z,
$$

where

$$
\boldsymbol{\sigma}=\left\{\begin{array}{lll}
\sigma_{x} & \sigma_{y} & \sigma_{x y}
\end{array}\right\}, \quad \boldsymbol{\varepsilon}=\left\{\begin{array}{lll}
\varepsilon_{x} & \varepsilon_{y} & \varepsilon_{x y}
\end{array}\right\}^{\mathrm{T}},
$$

$\boldsymbol{\sigma}=\boldsymbol{\varepsilon}^{\mathrm{T}} \mathbf{E}$, and the material constitutive matrix $\mathbf{E}$ of the shell is

$$
\mathbf{E}=\frac{E}{1-\mu^{2}}\left[\begin{array}{ccc}
1 & \mu & 0 \\
\mu & 1 & 0 \\
0 & 0 & \frac{(1-\mu)}{2}
\end{array}\right],
$$

where $E$ and $\mu$ are Young's modulus and Poisson ratio of the shell material, respectively.

Combining (1)-(6), one can obtain

$$
\begin{aligned}
V_{\text {sh }}=\frac{1}{2} D \int_{0}^{a} \int_{0}^{b}[ & \left(\frac{\partial^{2} w}{\partial x^{2}}\right)^{2}+\left(\frac{\partial^{2} w}{\partial y^{2}}\right)^{2} \\
& +2 \mu\left(\frac{\partial^{2} w}{\partial x^{2}}\right)\left(\frac{\partial^{2} w}{\partial y^{2}}\right) \\
& \left.+\frac{1-\mu}{2}\left(2 \frac{\partial^{2} w}{\partial x \partial y}\right)^{2}\right] \mathrm{d} x \mathrm{~d} y \\
+\frac{1}{2} G \int_{0}^{a} \int_{0}^{b}[ & \left(\frac{\partial u}{\partial x}+\frac{w}{R_{a}}\right)^{2}+\left(\frac{\partial v}{\partial y}+\frac{w}{R_{b}}\right)^{2} \\
& +2 \mu\left(\frac{\partial u}{\partial x}+\frac{w}{R_{a}}\right)\left(\frac{\partial v}{\partial y}+\frac{w}{R_{b}}\right) \\
& \left.+\frac{1-\mu}{2}\left(\frac{\partial u}{\partial y}+\frac{\partial v}{\partial x}\right)^{2}\right] \mathrm{d} x \mathrm{~d} y
\end{aligned}
$$

$$
\begin{gathered}
-D\left(\frac{1}{R_{a}}+\frac{1}{R_{b}}\right) \\
\times \int_{0}^{a} \int_{0}^{b}\left[\left(\frac{\partial u}{\partial x}+\frac{w}{R_{a}}\right)\left(\frac{\partial^{2} w}{\partial x^{2}}+\mu \frac{\partial^{2} w}{\partial y^{2}}\right)\right. \\
+\left(\frac{\partial v}{\partial y}+\frac{w}{R_{b}}\right)\left(\frac{\partial^{2} w}{\partial y^{2}}+\mu \frac{\partial^{2} w}{\partial x^{2}}\right) \\
\left.+\frac{1-\mu}{2}\left(\frac{\partial u}{\partial y}+\frac{\partial v}{\partial x}\right)\left(2 \frac{\partial^{2} w}{\partial x \partial y}\right)\right] \mathrm{d} x \mathrm{~d} y \\
+O\left(h^{4}\right),
\end{gathered}
$$

where $O\left(h^{4}\right)$ is a higher-order in $h$ and can be neglected here and $D=E h^{3} /\left[12\left(1-\mu^{2}\right)\right]$ and $G=E h /\left(1-\mu^{2}\right)$ are the bending rigidity and extensional rigidity of the shell, respectively. Equation (7) includes three terms which can be interpreted as bending energy, membrane energy, and coupling energy.

The potential energies stored in the boundary springs can be written as

$V_{\mathrm{sp}}$

$$
\begin{aligned}
= & \left.\frac{1}{2} \int_{0}^{a}\left[k_{y_{0}}^{f} w^{2}+k_{y_{0}}^{l} u^{2}+k_{y_{0}}^{t} v^{2}+K_{y_{0}}\left(\frac{\partial w}{\partial y}\right)^{2}\right]\right|_{y=0} \mathrm{~d} x \\
& +\left.\frac{1}{2} \int_{0}^{a}\left[k_{y_{b}}^{f} w^{2}+k_{y_{b}}^{l} u^{2}+k_{y_{b}}^{t} v^{2}+K_{y_{b}}\left(\frac{\partial w}{\partial y}\right)^{2}\right]\right|_{y=b} \mathrm{~d} x \\
& +\left.\frac{1}{2} \int_{0}^{b}\left[k_{x_{0}}^{f} w^{2}+k_{x_{0}}^{l} u^{2}+k_{x_{0}}^{t} v^{2}+K_{x_{0}}\left(\frac{\partial w}{\partial x}\right)^{2}\right]\right|_{x=0} \mathrm{~d} y \\
& +\left.\frac{1}{2} \int_{0}^{b}\left[k_{x_{a}}^{f} w^{2}+k_{x_{a}}^{l} u^{2}+k_{x_{a}}^{t} v^{2}+K_{x_{a}}\left(\frac{\partial w}{\partial x}\right)^{2}\right]\right|_{x=a} \mathrm{~d} y .
\end{aligned}
$$

The definitions for all the boundary springs are given in the Nomenclature.

The total kinetic energy of the doubly curved shallow shell, by neglecting rotary inertia, is given as

$$
T=\frac{1}{2} \rho h \int_{0}^{a} \int_{0}^{b}\left[\left(\frac{\partial u}{\partial t}\right)+\left(\frac{\partial v}{\partial t}\right)+\left(\frac{\partial w}{\partial t}\right)\right] \mathrm{d} x \mathrm{~d} y
$$

where $\rho$ is the mass density of the shell.

The displacements of a doubly curved shallow shell can be expressed as [34]

$$
\begin{aligned}
& u(x, y)=\sum_{m=-2}^{\infty} \sum_{n=-2}^{\infty} U_{m, n} \varphi_{m}(x) \varphi_{n}(y), \\
& v(x, y)=\sum_{m=-2}^{\infty} \sum_{n=-2}^{\infty} V_{m, n} \varphi_{m}(x) \varphi_{n}(y), \\
& w(x, y)=\sum_{m=-4}^{\infty} \sum_{n=-4}^{\infty} W_{m, n} \varphi_{m}(x) \varphi_{n}(y),
\end{aligned}
$$


TABLE 1: Frequency parameters for a completely clamped doubly curved shallow shell.

\begin{tabular}{|c|c|c|c|c|c|c|c|c|c|c|}
\hline \multirow[b]{2}{*}{ Mode number } & \multicolumn{10}{|c|}{ Mode frequencies } \\
\hline & 6 & 7 & 8 & $\begin{array}{c}M=N \\
9\end{array}$ & 10 & 11 & 12 & FEM $^{*}$ & $\mathrm{FEM}^{\#}$ & {$[14]$} \\
\hline$\overline{1}$ & 102.17 & 102.15 & 102.14 & 102.13 & 102.13 & 102.13 & 102.13 & 102.11 & 102.12 & 102.22 \\
\hline 2 & 103.02 & 103.01 & 103.00 & 103.00 & 103.00 & 103.00 & 103.00 & 103.00 & 103.01 & 103.08 \\
\hline 3 & 118.73 & 118.65 & 118.64 & 118.62 & 118.61 & 118.60 & 118.60 & 118.56 & 118.59 & 118.76 \\
\hline 4 & 144.73 & 144.72 & 144.71 & 144.71 & 144.71 & 144.71 & 144.71 & 144.63 & 144.66 & 144.82 \\
\hline 5 & 145.47 & 145.45 & 145.38 & 145.37 & 145.36 & 145.35 & 145.35 & 145.26 & 145.30 & 145.64 \\
\hline 6 & 158.54 & 158.53 & 158.52 & 158.51 & 158.51 & 158.51 & 158.51 & 158.43 & 158.46 & 158.67 \\
\hline Time (s) & 4.41 & 6.11 & 8.71 & 12.11 & 16.35 & 22.31 & 28.35 & 23.20 & 134.60 & \\
\hline
\end{tabular}

${ }^{*} 100 \times 100$ elements, ${ }^{\#} 200 \times 200$ elements.

where $U_{m, n}, V_{m, n}$, and $W_{m, n}$ denote the unknown trigonometric series coefficients to be determined and the basis functions are defined as

$$
\begin{array}{cl}
\varphi_{m}(x)=\cos \lambda_{a m} x & m \geq 0, \\
\varphi_{m}(x)=\sin \lambda_{a m} x & m<0, \\
\varphi_{n}(y)=\cos \lambda_{b n} y & n \geq 0, \\
\varphi_{n}(y)=\sin \lambda_{b n} y & n<0,
\end{array}
$$

where $\lambda_{a m}=m \pi / a$ and $\lambda_{b n}=n \pi / b$. Since trigonometric series are "invariants" under differential and integral operations, the current displacement expressions are much more attractive. It can be mathematically proven that the trigonometric series expansions, (10)-(12), are better suited for expanding a sufficiently smooth function defined over a compact interval, respectively, and converge uniformly over the solution domain. As a matter of fact, (10) is able to expand to any function $f(x, y) \in C^{3}$ for $\forall(x, y) \in D:([0, a] \otimes$ $[0, b])$. So the current displacement solutions are simply those elements in the vector space which simultaneously satisfy both the governing differential equations and the boundary conditions on a point-wise basis. It can be seen that the inplane displacements $u(x, y)$ and $v(x, y)$ have less sine terms than the out-of-plane displacement $w(x, y)$ because they are only required to have $C^{1}$ continuity over the shell.

The Lagrangian $L$ for the doubly curved shallow shell can be generally expressed as

$$
L=V-T=V_{\mathrm{sh}}+V_{\mathrm{sp}}-T,
$$

where $V$ is the total potential energy of the shell. Substituting (7)-(9) into (14) and minimizing Lagrangian with respect to all the unknown series coefficients, one can obtain a system of linear algebraic equations in matrix form

$$
\left(\mathbf{K}-\omega^{2} \mathbf{M}\right) \mathbf{A}=\mathbf{0},
$$

where $\mathbf{A}$ is a vector that contains all the unknown series expansion coefficients and is defined as

$$
\mathbf{A}=\left[\begin{array}{lll}
\mathbf{U}^{\mathrm{T}} & \mathbf{V}^{\mathrm{T}} & \mathbf{W}^{\mathrm{T}}
\end{array}\right]^{\mathrm{T}},
$$

where

$$
\begin{gathered}
\mathbf{U}=\left\{U_{-2,-2}, U_{-2,-1}, \ldots, U_{-2, n}, \ldots, U_{-2, N}, U_{-1,-2}, \ldots,\right. \\
\left.U_{-1, N}, \ldots, U_{m, N}, \ldots, U_{M-1, N}, U_{M,-2}, \ldots, U_{M, N}\right\}^{\mathrm{T}}, \\
\mathbf{V}=\left\{V_{-2,-2}, V_{-2,-1}, \ldots, V_{-2, n}, \ldots, V_{-2, N}, V_{-1,-2}, \ldots,\right. \\
\\
\left.V_{-1, N}, \ldots, V_{m, N}, \ldots, V_{M-1, N}, V_{M,-2}, \ldots, V_{M, N}\right\}^{\mathrm{T}}, \\
\mathbf{W}=\left\{W_{-4,-4}, W_{-4,-3}, \ldots, W_{-4, n}, \ldots, W_{-4, N}, W_{-3,-4}, \ldots,\right. \\
\\
\left.W_{-3, N}, \ldots, W_{m, N}, \ldots, W_{M-1, N}, W_{M,-4}, \ldots, W_{M, N}\right\}^{\mathrm{T}} .
\end{gathered}
$$

$M$ and $N$ are truncation numbers of the trigonometric expansion series. $\mathbf{K}$ and $\mathbf{M}$ stand for the stiffness and mass matrices, respectively. The detailed expressions for these matrices are given in the Appendix.

By solving a standard matrix eigenvalue problem, modal properties of the doubly curved shallow shell can be readily and directly determined. Since each of the eigenvectors actually contains the trigonometric series coefficients, the corresponding physical mode shape of the shell can be simply obtained by using the displacement expressions, (10)-(12). It should be pointed out that although this paper is focused on the free vibration of doubly curved shallow shells, its response to an applied load can be easily calculated by including the work done by this load in the Lagrangian, eventually leading to a force term on the right side of (15). Once the primary solution variables, displacements, are determined over the shell, other dynamic variables of interest can be readily calculated by directly apply appropriate mathematical operations to the displacement functions.

\section{Results and Discussions}

Accuracy and convergence of the current method will be demonstrated in this section by numerical results firstly. Consider a doubly curved shallow shell with fully clamped along four edges (C-C-C-C). The clamped edge can be regarded as a special case when the stiffnesses for all the boundary restraining springs become infinitely large (which is actually represented by a very lager number, $2.0 \times 10^{12}$, in the numerical calculations). The first six nondimensional frequency parameters, $\Omega=\omega l_{a} l_{b} \sqrt{\rho h / D}$, which are determined using different numbers of expansion terms $M$ and $N$ are listed in Table 1 with the following geometric parameters: 

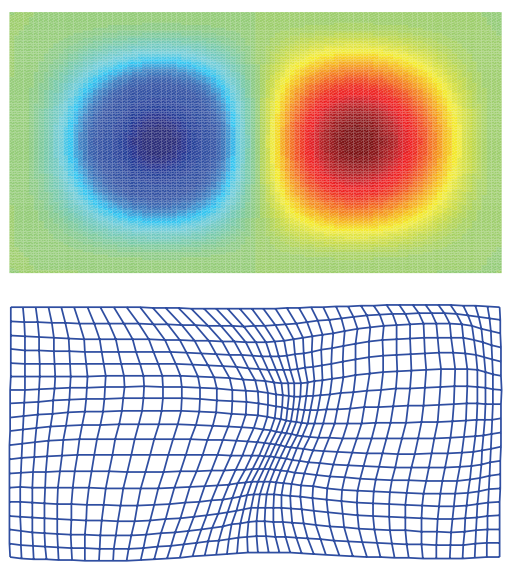

(a)
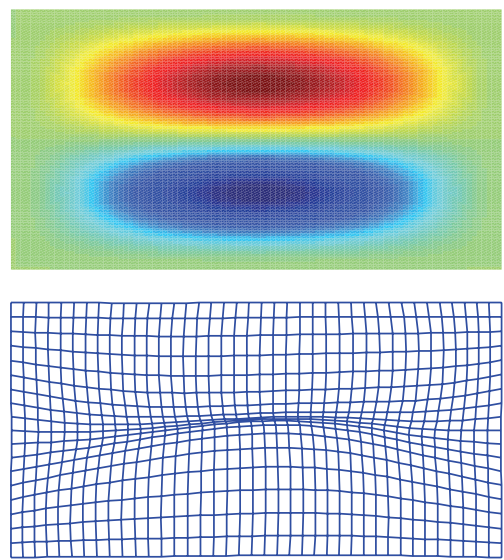

(d)
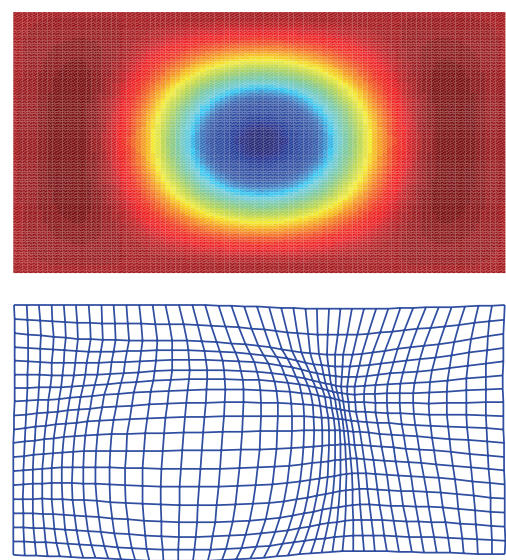

(b)
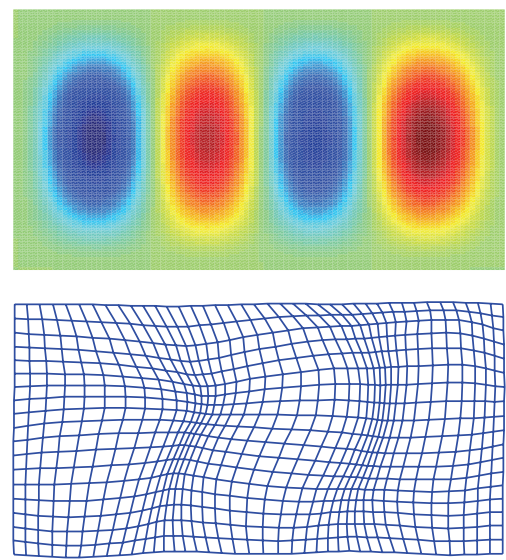

(e)
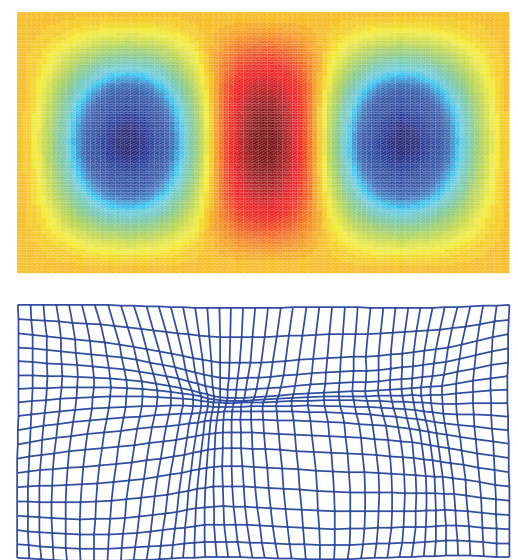

(c)
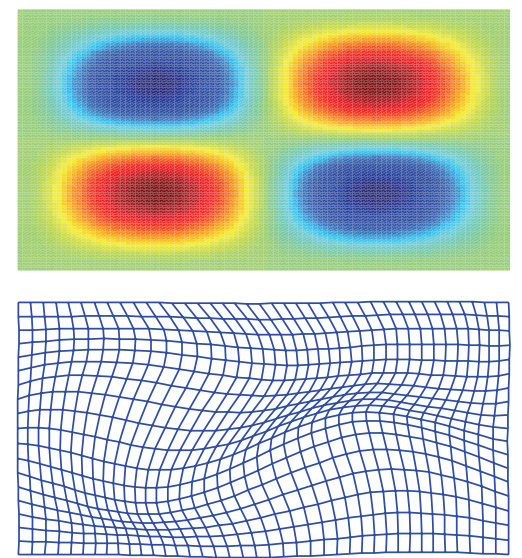

(f)

FIGURE 3: The mode shapes (above: out-of-plane mode shapes; below: in-plane mode shapes) for a doubly curved shallow shell with completely clamped edges: The (a) first, (b) second, (c) third, (d) fourth, (e) fifth, and (f) sixth mode.

$R_{b} / R_{a}=1, R_{b} / l_{b}=10, l_{a} / l_{b}=2, l_{b} / h=100$, and $\mu=0.3$. The results compare very well with those obtained from the finite element method and [14]. Since it can be seen that the current results converge rapidly with a small number of expansion terms and have great numerical stability, the displacement series expansions will be truncated to $M=N=$ 12 in all the following calculations. The corresponding mode shapes are plotted in Figure 3. It is shown that the in-plane two directional displacements are coupled together at any field point. The solution times between the current method and finite element method are also compared in Table 1. Due to the models that are both small, the time given in Table 1 is not conclusive regarding which method is more effective computationally. However, the effectiveness of the current method over the FEA has been adequately demonstrated in a previous support [35] in which the modified Fourier series method is shown to cut computing time by two orders of magnitude as compared with the FEM model used to simulate a box-like structure in frequency response analysis.

Next example concerns completely free (F-F-F-F) shallow shells having square and rectangular planform. The completely free boundary condition represents a classical, but quite challenging, case for testing a shell solution. Under the current framework, the free edge condition is easily realized by setting all the stiffness constants to zero. Eight frequency parameters, $\Omega=\omega l_{a}^{2} \sqrt{\rho h / D}$, are listed in Table 2 for different curvature ratios (where $\mathrm{S}$ or $\mathrm{A}$ is used to indicate that a vibration mode is symmetric (S) or antisymmetric (A) with respect to the $x$ - or $y$-axis). Two sets of reference results are also given there for comparison, and these three sets of solutions agree well with each other.

To further validate the accuracy and reliability of the proposed analytical method, Table 3 shows frequency parameters $\Omega=\omega l_{a}^{2} \sqrt{\rho h / D}$ for a few more classical cases $(\mathrm{F}$ F-F-F, C-F-F-F, C-C-F-F, C-F-C-F, C-C-C-F and C-C-C-C). The reference results from [16] and FEM models are also given there for comparison. Traditionally, the displacement expressions and the subsequent solution algorithms and implementations are dictated by the intended boundary condition. Consequently, most studies are specifically related to a particular type of boundary conditions. In the above examples, it has been demonstrated that the proposed analytical method can be universally applied to different boundary conditions with no need of making any algorithm or procedural modifications; the modifying boundary conditions are as simple as changing shell parameters such as geometrical 
TABLE 2: Frequency parameters of completely free shallow shells having square and rectangular planform $\left(l_{a} / R_{a}=0.2, l_{a} / h=100\right.$, and $\mu=0.3)$.

\begin{tabular}{|c|c|c|c|c|c|c|c|}
\hline \multirow{2}{*}{$R_{a} / R_{b}$} & \multirow{2}{*}{ Mode } & \multicolumn{3}{|c|}{$l_{a} / l_{b}=1$} & \multicolumn{3}{|c|}{$l_{a} / l_{b}=2$} \\
\hline & & Current & [15] & FEM & Current & [15] & FEM \\
\hline \multirow{8}{*}{1} & SS-1 & 19.691 & 19.757 & 19.733 & 22.721 & 22.794 & 22.709 \\
\hline & SS-2 & 42.235 & 42.353 & 42.127 & 98.601 & 99.041 & 98.593 \\
\hline & SA-1 & 35.764 & 35.880 & 35.790 & 58.439 & 58.574 & 58.450 \\
\hline & SA-2 & 73.624 & 73.890 & 73.544 & 160.51 & 172.23 & 160.53 \\
\hline & AS-1 & 35.764 & 35.880 & 35.790 & 62.120 & 62.345 & 62.126 \\
\hline & AS-2 & 73.624 & 73.890 & 73.544 & 110.65 & 110.83 & 110.58 \\
\hline & AA-1 & 13.480 & 13.524 & 13.491 & 26.521 & 26.577 & 26.531 \\
\hline & AA-2 & 69.342 & 69.598 & 69.480 & 101.68 & 102.00 & 101.69 \\
\hline \multirow{8}{*}{0} & SS-1 & 21.831 & 21.904 & 21.810 & 21.559 & 21.631 & 21.538 \\
\hline & SS-2 & 38.495 & 38.473 & 38.510 & 100.28 & 100.55 & 100.28 \\
\hline & SA-1 & 34.771 & 34.852 & 34.737 & 58.310 & 58.425 & 58.252 \\
\hline & SA-2 & 75.278 & 75.298 & 75.281 & 159.78 & 171.56 & 159.74 \\
\hline & AS-1 & 37.625 & 37.643 & 37.623 & 59.613 & 59.845 & 59.585 \\
\hline & AS-2 & 60.914 & 61.154 & 60.886 & 109.53 & 109.60 & 109.53 \\
\hline & AA-1 & 13.461 & 13.483 & 13.467 & 26.517 & 26.562 & 26.520 \\
\hline & AA-2 & 70.765 & 70.952 & 70.740 & 101.24 & 101.53 & 101.20 \\
\hline \multirow{8}{*}{-1} & SS-1 & 24.659 & 24.741 & & 25.216 & 25.294 & \\
\hline & SS-2 & 52.538 & 52.574 & & 102.11 & 102.19 & \\
\hline & SA-1 & 36.842 & 36.957 & & 58.407 & 58.543 & \\
\hline & SA-2 & 76.865 & 77.063 & & 160.72 & 172.64 & \\
\hline & AS-1 & 36.842 & 36.957 & & 66.341 & 66.576 & \\
\hline & AS-2 & 76.865 & 77.063 & & 108.95 & 109.07 & \\
\hline & AA-1 & 13.418 & 13.425 & & 26.508 & 26.564 & \\
\hline & AA-2 & 77.349 & 77.647 & & 101.69 & 102.00 & \\
\hline
\end{tabular}

and material properties. Consider the simply supported case (SSSS) for example. It can be produced easily by letting the stiffnesses of the three linear springs be infinitely large and the stiffness of the rotational spring zero. Similarly, singly curved shells can be considered as special cases when one of curvatures becomes zero, as illustrated in Table 4 for various boundary conditions.

All the examples considered thus far have been limited to the classical boundary conditions which are viewed as the special cases of elastically restrained edges. We now turn to elastically restrained shells. The stiffnesses of the linear and rotational restraints are set equal to $k=10^{6}$ and $K=$ $10^{7}$, respectively. The first eight frequency parameters $\Omega=$ $\omega l_{a}^{2} \sqrt{\rho h / D}$ are listed in Table 5 with the following geometric parameters: $R_{a} / R_{b}=1, R_{a} / l_{a}=10, l_{a} / l_{b}=1, l_{b} / h=200$, and $\mu=0.3$. The corresponding mode shapes are plotted in Figure 4. It can be seen from Figure 4 that these lower order modes exhibit complicated spatial patterns. Moreover, the inplane patterns tend to be more local and are typically more complicated than their out-of-plane counterpart. Through those modes, one can easily understand the "unpredictable" behaviors of a doubly curved shallow shell and the effects of curvatures and boundary conditions.

Effects of curvature on the vibration characteristics of shallow shells are studied in this section. It is assumed that the geometric parameters of the shell are $l_{a} / l_{b}=1$ and $l_{b} / h=100$ and Poisson's ratio $\mu=0.3$ in the following calculations. Tables $6,7,8,9$, and 10 show the first frequency parameters $\Omega$ of shallow shells having different $x$-direction curvature $\left(1 / R_{a}\right)$ and $y$-direction curvature $\left(1 / R_{b}\right)$ with $\mathrm{C}-\mathrm{C}-\mathrm{C}-\mathrm{C}, \mathrm{C}$ C-C-F, C-F-C-F, C-F-F-F, and F-F-F-F boundary conditions. The free edge condition ( $\mathrm{F}$ ) is easily simulated by setting the stiffnesses for the boundary restraining springs to zero.

Figures 5(a)-5(e) show the changes in the frequency parameters $\Omega=\omega l_{a} l_{b} \sqrt{\rho h / D}$ for the first modes of shallow shells with five different boundary conditions, which are listed in Tables $6-10$, as the curvature ratio $R_{b} / R_{a}$ is varied from -1 to 1 , respectively. The curves are drawn beginning with a flat plate $\left(l_{b} / R_{b}=0\right)$ and changing the $y$-direction curvature. Thus, the change in circular frequency $\omega$ with changing $1 / R_{b}$ is observed for fixed $l_{a}, \rho, h, E$, and $\mu(D=$ $\left.E h^{3} /\left[12\left(1-\mu^{2}\right)\right]\right)$ and fixed $l_{b}\left(l_{a} / l_{b}=1\right)$ by changing $l_{b} / R_{b}$.

It can be seen from Figure 5(a) that, for a C-C-C-C shell, increasing $y$-direction curvature can causes a considerable increase in the first mode frequency, and giving the shell significant additional $x$-direction curvature, either positive or negative, can cause an increase in the first mode frequency too. It also can be found from Figure 5(a) that the first mode frequency for the shell of positive Gaussian curvature is greater than that having negative Gaussian curvature with 
TABLE 3: Frequency parameters of shallow shells with different boundary conditions $\left(l_{a} / R_{b}=0.2, l_{a} / l_{b}=1, l_{a} / h=20\right.$, and $\left.\mu=0.3\right)$.

\begin{tabular}{|c|c|c|c|c|c|c|c|}
\hline \multirow{2}{*}{$R_{a} / R_{b}$} & \multirow{2}{*}{ Mode number } & \multicolumn{6}{|c|}{ Boundary conditions } \\
\hline & & F-F-F-F & C-F-F-F & C-C-F-F & C-F-C-F & $\mathrm{C}-\mathrm{C}-\mathrm{C}-\mathrm{F}$ & $\mathrm{C}-\mathrm{C}-\mathrm{C}-\mathrm{C}$ \\
\hline \multirow{12}{*}{1} & \multirow{3}{*}{1} & 13.41 & 3.739 & 7.860 & 25.28 & 26.79 & 40.27 \\
\hline & & $\left(13.46^{\mathrm{a}}\right)$ & $(3.754)$ & $(7.894)$ & $(25.30)$ & $(26.62)$ & $(40.26)$ \\
\hline & & {$\left[13.43^{\mathrm{b}}\right]$} & {$[3.756]$} & {$[7.891]$} & {$[25.32]$} & {$[26.84]$} & [40.25] \\
\hline & \multirow{3}{*}{2} & 19.50 & 8.456 & 23.80 & 25.28 & 42.58 & 74.43 \\
\hline & & $\left(19.56^{\mathrm{a}}\right)$ & $(8.492)$ & $(23.90)$ & $(25.30)$ & $(42.71)$ & $(74.17)$ \\
\hline & & {$\left[19.54^{\mathrm{b}}\right]$} & [8.467] & [23.84] & [25.32] & [42.57] & [74.39] \\
\hline & \multirow{3}{*}{3} & 25.92 & 21.44 & 27.83 & 45.44 & 63.39 & 74.43 \\
\hline & & $\left(25.99^{\mathrm{a}}\right)$ & $(21.53)$ & $(27.92)$ & $(45.53)$ & $(63.56)$ & $(74.17)$ \\
\hline & & {$\left[25.82^{\mathrm{b}}\right]$} & [21.46] & [27.78] & [45.45] & [63.41] & [74.39] \\
\hline & \multirow{3}{*}{4} & 34.72 & 28.17 & 49.08 & 61.32 & 77.62 & 108.7 \\
\hline & & $\left(34.85^{\mathrm{a}}\right)$ & $(28.26)$ & $(49.27)$ & $(61.34)$ & $(77.64)$ & $(108.7)$ \\
\hline & & {$\left[34.73^{\mathrm{b}}\right]$} & [28.12] & [49.09] & [61.33] & {$[77.60]$} & [108.7] \\
\hline \multirow{12}{*}{$\infty$} & \multirow{3}{*}{1} & 13.44 & 3.802 & 7.201 & 22.72 & 24.44 & 37.75 \\
\hline & & $\left(13.46^{\mathrm{a}}\right)$ & $(3.806)$ & $(7.218)$ & $(22.36)$ & $(24.34)$ & $(37.56)$ \\
\hline & & {$\left[13.45^{\mathrm{b}}\right]$} & [3.807] & [7.216] & [22.73] & [24.46] & [37.75] \\
\hline & \multirow{3}{*}{2} & 20.08 & 8.507 & 24.23 & 26.46 & 40.47 & 73.31 \\
\hline & & $\left(20.12^{\mathrm{a}}\right)$ & $(8.526)$ & $(24.30)$ & (26.43) & $(40.53)$ & (72.59) \\
\hline & & {$\left[20.07^{\mathrm{b}}\right]$} & [8.509] & [24.23] & [26.47] & [40.46] & [73.30] \\
\hline & \multirow{3}{*}{3} & 24.74 & 21.96 & 27.03 & 43.63 & 63.65 & 74.28 \\
\hline & & $\left(24.77^{\mathrm{a}}\right)$ & (21.98) & (27.08) & (43.59) & $(62.56)$ & $(72.66)$ \\
\hline & & {$\left[24.73^{\mathrm{b}}\right]$} & [21.96] & [27.02] & [43.63] & [63.69] & [74.30] \\
\hline & \multirow{3}{*}{4} & 34.70 & 27.21 & 48.09 & 61.67 & 76.58 & 108.3 \\
\hline & & $\left(34.79^{\mathrm{a}}\right)$ & $(27.29)$ & $(48.21)$ & (61.59) & $(76.47)$ & (108.4) \\
\hline & & {$\left[34.67^{\mathrm{b}}\right]$} & [27.19] & [48.08] & [61.70] & [76.57] & [108.3] \\
\hline \multirow{8}{*}{-1} & \multirow{2}{*}{1} & 13.41 & 3.794 & 7.041 & 25.06 & 26.68 & 38.59 \\
\hline & & $\left(13.46^{\mathrm{a}}\right)$ & $(3.814)$ & $(7.071)$ & (25.07) & (26.78) & $(38.51)$ \\
\hline & \multirow{2}{*}{2} & 21.84 & 8.444 & 25.47 & 28.57 & 41.54 & 74.02 \\
\hline & & $\left(21.90^{\mathrm{a}}\right)$ & $(8.480)$ & (25.58) & $(28.62)$ & $(41.60)$ & (74.09) \\
\hline & \multirow{2}{*}{3} & 24.16 & 22.28 & 26.92 & 44.82 & 63.48 & 74.02 \\
\hline & & $\left(24.24^{\mathrm{a}}\right)$ & $(22.38)$ & $(27.03)$ & $(44.92)$ & $(63.92)$ & (73.97) \\
\hline & \multirow{2}{*}{4} & 34.81 & 27.80 & 48.02 & 61.44 & 77.31 & 108.1 \\
\hline & & $\left(34.94^{\mathrm{a}}\right)$ & $(27.89)$ & $(48.22)$ & (61.47) & $(77.26)$ & (108.0) \\
\hline
\end{tabular}

${ }^{\mathrm{a}}$ Results from [16].

${ }^{\mathrm{b}}$ Results are obtained from FEM models.

the same absolute value. With increasing the $y$-direction curvature, difference of the first mode frequencies between spherical shell $\left(R_{b} / R_{a}=1\right)$ and hyperbolic paraboloidal shell $\left(R_{b} / R_{a}=-1\right)$ becomes more and more large. Figure 5(a) also shows that the minimum value of the first mode frequency occurs for the shell having slightly negative Gaussian curvature and the point of minima is shifted to the left with decreasing $l_{b} / R_{b}$.

For a C-C-C-F shallow shell, which means that the stiffness constants of the restraining springs at edge $y=0$ are equal to zero, the first mode frequency increases gradually with increasing the $y$-direction curvature as shown in Figure 5(b). Frequency of the first mode also increases rapidly through adding the $x$-direction curvature. But the increase trend of the first mode frequency becomes slow when the absolute value of curvature ratio $R_{b} / R_{a}$ is comparatively large.
It is more obvious if the Gaussian curvature is positive. The curvature effects on the first mode frequency for the C-F-C-F shell and the C-C-C-F shell are almost the same, which can be seen in Figure 5(c).

The shapes of curves in Figure 5(d) are different. Although the first mode frequency of a C-F-F-F shell increases gradually with the increasing of $y$-direction curvature, it decreases if giving the shell significant additional $x$-direction curvature, which is just the opposite of the three boundary conditions mentioned above. Figure 5(d) also shows that, with $l_{b} / R_{b}$ decreasing from 0.5 to 0.1 , the difference of the first mode frequencies between spherical shell $\left(R_{b} / R_{a}=1\right)$ and hyperbolic paraboloidal shell $\left(R_{b} / R_{a}=-1\right)$ is varied gradually from positive number to negative number.

Figure 5(e) shows the first mode frequency as a function of curvature ratio for an F-F-F-F shell. It can be seen that 
TABLE 4: Frequency parameters for different boundary condition singly curved shallow shells with thickness ratio $h / l_{b}=100(\mu=0.3)$.

\begin{tabular}{|c|c|c|c|c|c|c|c|c|}
\hline \multirow{2}{*}{$\mathrm{BC}$} & \multirow{2}{*}{$l_{a} / l_{b}$} & \multirow{2}{*}{$l_{b} / R_{b}$} & \multicolumn{6}{|c|}{ Mode number } \\
\hline & & & 1 & 2 & 3 & 4 & 5 & 6 \\
\hline \multirow{9}{*}{ S-F-S-F } & \multirow{4}{*}{0.5} & \multirow{2}{*}{0.1} & 22.199 & 24.194 & 36.289 & 55.883 & 79.506 & 83.045 \\
\hline & & & $\left(22.194^{\mathrm{a}}\right)$ & $(24.178)$ & $(36.262)$ & $(55.824)$ & $(79.487)$ & $(83.002)$ \\
\hline & & \multirow{2}{*}{0.2} & 26.397 & 27.512 & 39.769 & 56.755 & 82.575 & 84.809 \\
\hline & & & $\left(26.375^{\mathrm{a}}\right)$ & (27.487) & $(39.788)$ & $(56.783)$ & $(82.540)$ & $(84.756)$ \\
\hline & \multirow{5}{*}{1.0} & \multirow{2}{*}{0.1} & 15.704 & 17.062 & 37.872 & 43.834 & 48.108 & 72.459 \\
\hline & & & $\left(15.693^{\mathrm{a}}\right)$ & $(17.042)$ & $(37.853)$ & $(43.811)$ & $(48.065)$ & (72.396) \\
\hline & & \multirow{3}{*}{0.2} & 19.498 & 24.284 & 42.410 & 51.796 & 53.554 & 75.946 \\
\hline & & & $\left(19.460^{\mathrm{a}}\right)$ & $(24.234)$ & $(42.446)$ & $(51.713)$ & $(53.469)$ & (76.087) \\
\hline & & & {$\left[19.446^{\mathrm{b}}\right]$} & [24.240] & [42.378] & [51.695] & [53.464] & [75.851] \\
\hline \multirow{9}{*}{ C-F-C-F } & \multirow{4}{*}{0.5} & \multirow{2}{*}{0.1} & 45.776 & 47.172 & 55.584 & 71.384 & 97.130 & 123.52 \\
\hline & & & $\left(45.782^{\mathrm{a}}\right)$ & $(47.176)$ & $(55.602)$ & $(71.414)$ & (97.187) & (123.53) \\
\hline & & \multirow{2}{*}{0.2} & 48.365 & 48.688 & 57.865 & 72.110 & 97.314 & 125.52 \\
\hline & & & $\left(48.373^{\mathrm{a}}\right)$ & $(48.697)$ & (57.905) & $(72.210)$ & $(97.514)$ & (125.53) \\
\hline & \multirow{5}{*}{1.0} & \multirow{2}{*}{0.1} & 25.463 & 26.982 & 44.584 & 64.445 & 68.153 & 79.963 \\
\hline & & & $\left(25.463^{\mathrm{a}}\right)$ & $(26.982)$ & $(44.608)$ & $(64.437)$ & $(68.152)$ & $(80.016)$ \\
\hline & & \multirow{3}{*}{0.2} & 28.587 & 31.671 & 48.595 & 70.853 & 71.644 & 80.405 \\
\hline & & & $\left(28.589^{\mathrm{a}}\right)$ & $(31.667)$ & $(48.653)$ & $(70.850)$ & $(71.626)$ & (80.608) \\
\hline & & & {$\left[28.576^{b}\right]$} & [31.673] & [48.580] & {$[70.813]$} & [71.617] & [80.372] \\
\hline \multirow{9}{*}{ S-S-S-S } & \multirow{4}{*}{0.5} & \multirow{2}{*}{0.1} & 29.363 & 41.242 & 64.852 & 85.445 & 99.035 & 99.911 \\
\hline & & & $\left(29.351^{\mathrm{a}}\right)$ & $(41.161)$ & $(64.753)$ & $(85.406)$ & (98.912) & (99.747) \\
\hline & & \multirow{2}{*}{0.2} & 40.018 & 45.813 & 66.603 & 89.807 & 99.491 & 102.93 \\
\hline & & & $\left(40.053^{\mathrm{a}}\right)$ & $(45.810)$ & $(66.625)$ & (89.789) & (99.568) & (102.83) \\
\hline & \multirow{5}{*}{1.0} & \multirow{2}{*}{0.1} & 36.804 & 51.608 & 58.413 & 82.449 & 99.526 & 103.72 \\
\hline & & & $\left(36.841^{\mathrm{a}}\right)$ & $(51.576)$ & (58.383) & $(82.302)$ & (99.527) & $(103.66)$ \\
\hline & & \multirow{3}{*}{0.2} & 57.644 & 63.712 & 79.167 & 91.551 & 102.61 & 117.24 \\
\hline & & & $\left(57.708^{\mathrm{a}}\right)$ & $(63.834)$ & $(79.217)$ & $(91.542)$ & $(102.84)$ & (117.23) \\
\hline & & & {$\left[57.581^{\mathrm{b}}\right]$} & [63.799] & [79.184] & [91.414] & [102.53] & [117.19] \\
\hline \multirow{9}{*}{ C-S-C-S } & & 01 & 50.190 & 59.063 & 78.651 & 109.62 & 128.06 & 139.39 \\
\hline & 0.5 & 0.1 & $\left(50.200^{\mathrm{a}}\right)$ & (59.082) & (78.688) & (109.69) & (128.07) & (139.41) \\
\hline & 0.5 & ? & 57.074 & 62.404 & 80.129 & 110.05 & 131.02 & 141.58 \\
\hline & & 0.2 & $\left(57.107^{\mathrm{a}}\right)$ & $(62.467)$ & $(80.267)$ & (110.31) & (131.04) & (141.64) \\
\hline & & 01 & 42.398 & 56.809 & 76.001 & 97.409 & 102.95 & 132.92 \\
\hline & & 0.1 & $\left(42.445^{\mathrm{a}}\right)$ & $(56.845)$ & $(76.022)$ & (97.448) & (103.03) & (132.94) \\
\hline & 1.0 & & 62.563 & 67.119 & 92.949 & 105.38 & 105.88 & 143.75 \\
\hline & & 0.2 & $\left(62.678^{\mathrm{a}}\right)$ & $(67.233)$ & (93.012) & $(105.52)$ & (106.18) & (143.80) \\
\hline & & & {$\left[62.559^{\mathrm{b}}\right]$} & {$[67.201]$} & [92.982] & [105.40] & [105.87] & [143.76] \\
\hline
\end{tabular}

${ }^{\mathrm{a}}$ Results from [17].

${ }^{\mathrm{b}}$ Results are obtained from FEM models.

TABLE 5: Frequency parameters of an elastically supported shallow shell.

\begin{tabular}{lccccccc}
\hline \multicolumn{7}{c}{ Mode number } \\
1 & 2 & 3 & 4 & 5 & 6 & 7 & 8 \\
\hline 33.008 & 41.067 & 41.067 & 46.364 & 46.364 & 57.091 & 58.083 & 64.769 \\
\hline
\end{tabular}

changing the curvature of a completely free shell does not have much effect on the first mode frequency. The difference between the maximum frequency and minimum frequency is no more than $0.35 \mathrm{~Hz}$. In general, increasing $y$-direction curvature causes a decreasing in the first mode frequency, which is different from the other four boundary conditions. The maximum value of the first mode frequency occurs for the shell having significant positive Gaussian curvature.

It is known that the value of the mode frequency depends on the mode stiffness and mode mass

$$
\omega_{m}^{2}=\frac{K_{m}}{M_{m}}
$$

where $\omega_{m}, K_{m}$, and $M_{m}$ denote the $m$ th mode frequency, mode stiffness, and mode mass, respectively. The mode frequency can be directly calculated since the mode stiffness 

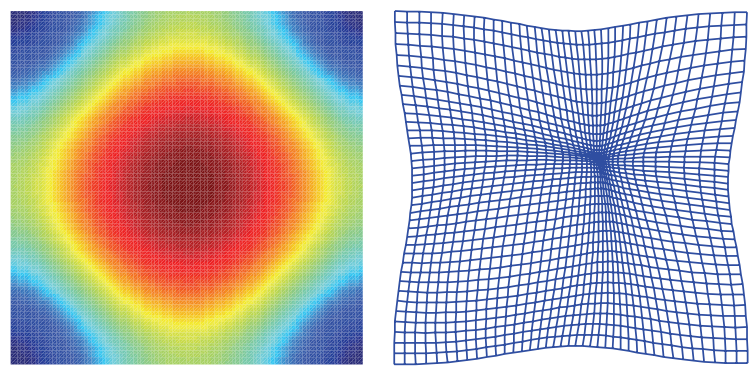

(a)
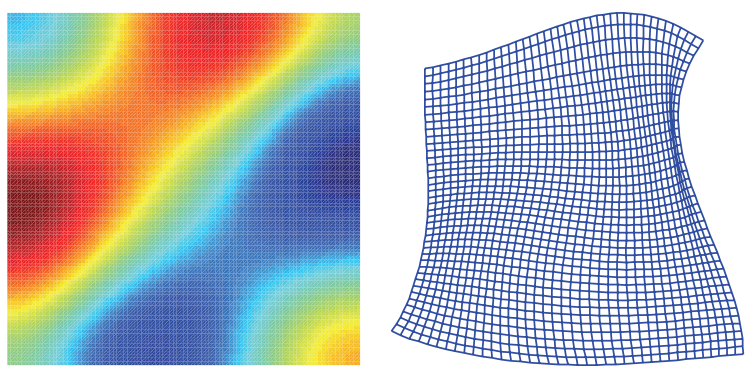

(c)
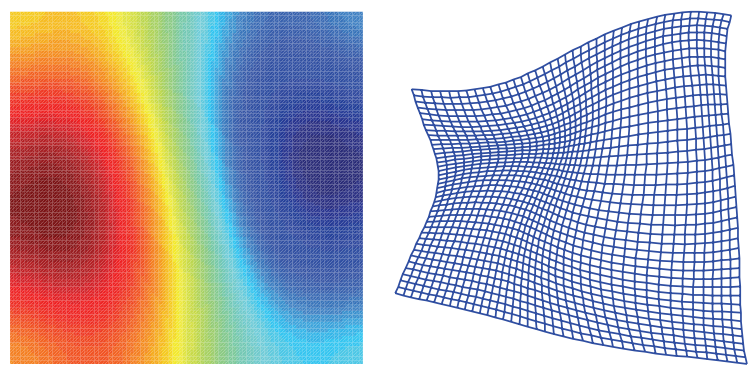

(e)
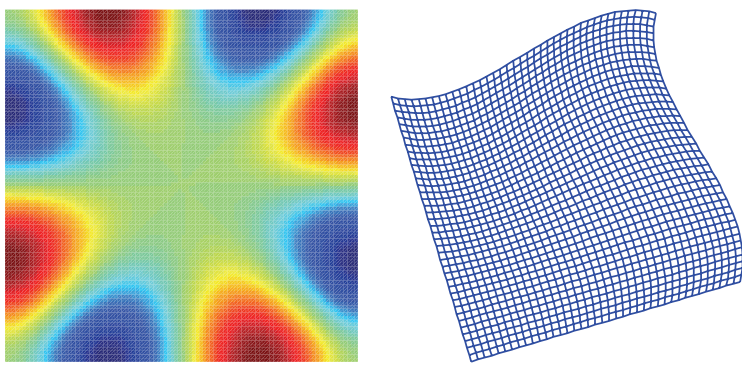

(g)
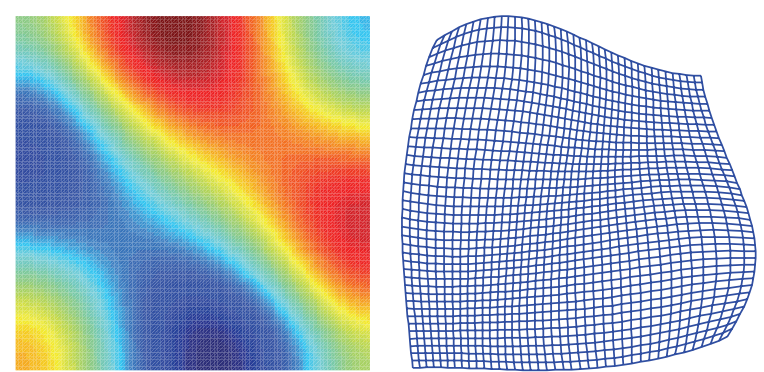

(b)
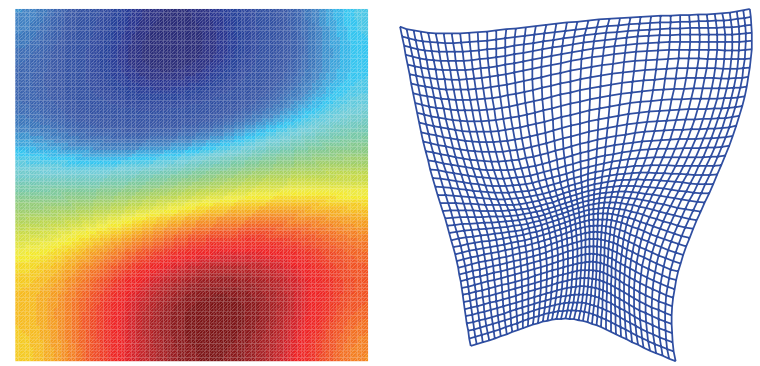

(d)
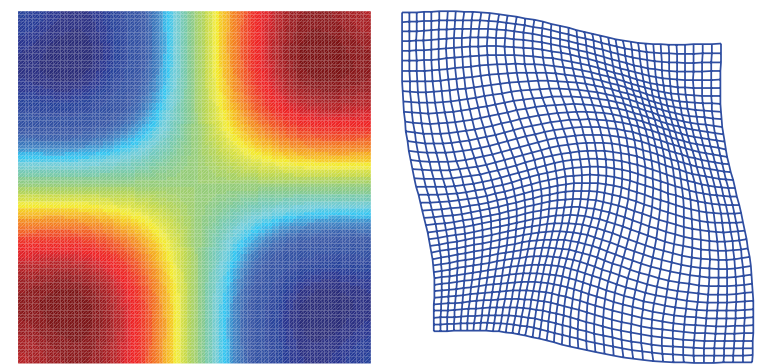

(f)
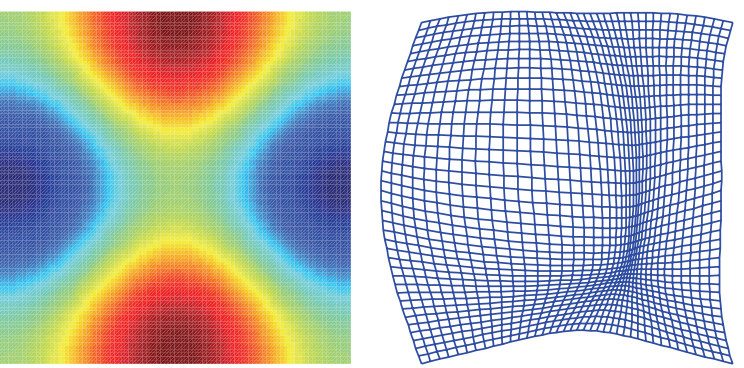

(h)

FIGURE 4: The mode shapes (left: out-of-plane mode shapes; right: in-plane mode shapes) for a doubly curved shallow shell with elastic restraints, $k=10^{6}$ and $K=10^{7}$, along each edge. The (a) first, (b) second, (c) third, (d) fourth, (e) fifth, (f) sixth (g) seventh, and (h) eighth mode.

and mode mass are the corresponding diagonal elements of the diagonal stiffness matrix and mass matrix of the shell which can be easily obtained through mathematical operations. Differentiating the square of mode frequency $\omega_{m}^{2}$ with respect to curvature ratio $R_{b} / R_{a}$,

$$
\frac{\partial \omega_{m}^{2}}{\partial\left(R_{b} / R_{a}\right)}=\frac{\partial\left(K_{m} / M_{m}\right)}{\partial\left(R_{b} / R_{a}\right)}
$$

When (19) is equal to zero, one can obtain

$$
\frac{K_{m}}{M_{m}}=\frac{\partial K_{m}}{\partial M_{m}} .
$$

So, one can say that the extremum value of the $m$ th mode frequency occurs when $K_{m} / M_{m}$ is equal to $\partial K_{m} / \partial M_{m}$.

Two examples are given here to verify the conclusion. The first example is one case in Figure 5(a). The change in 


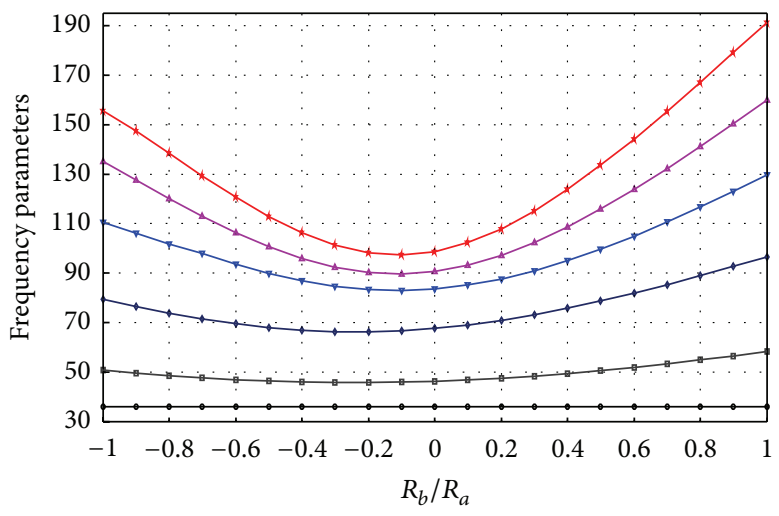

(a)

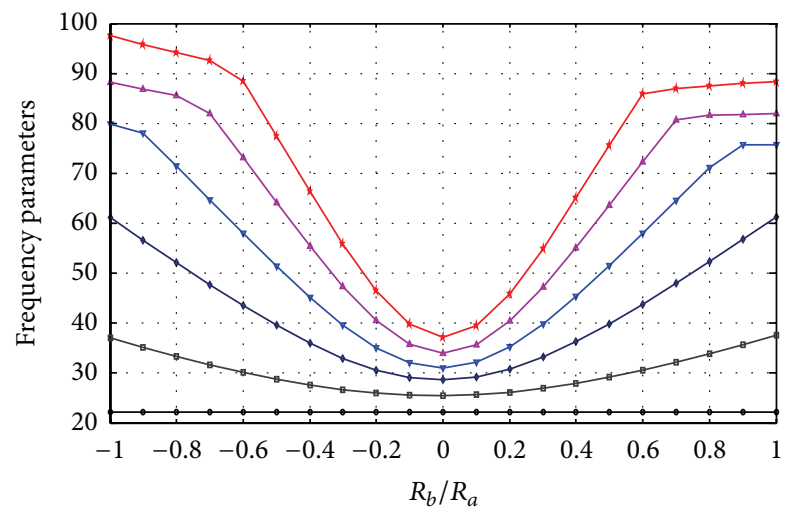

(c)

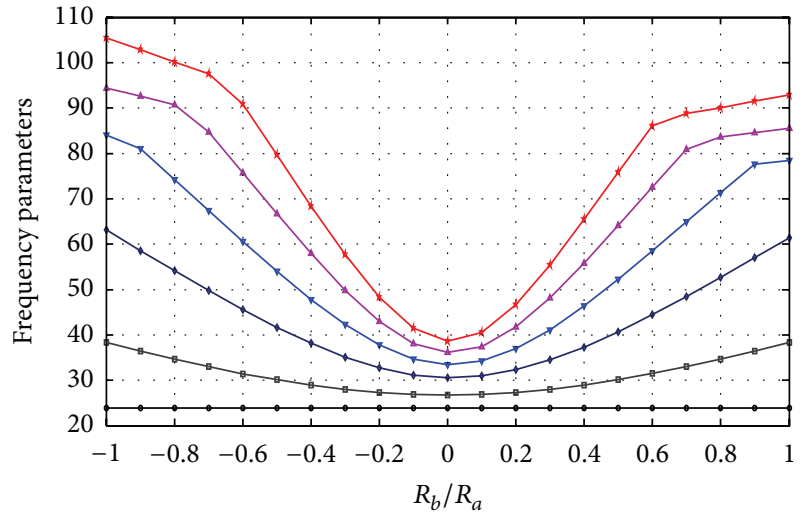

(b)

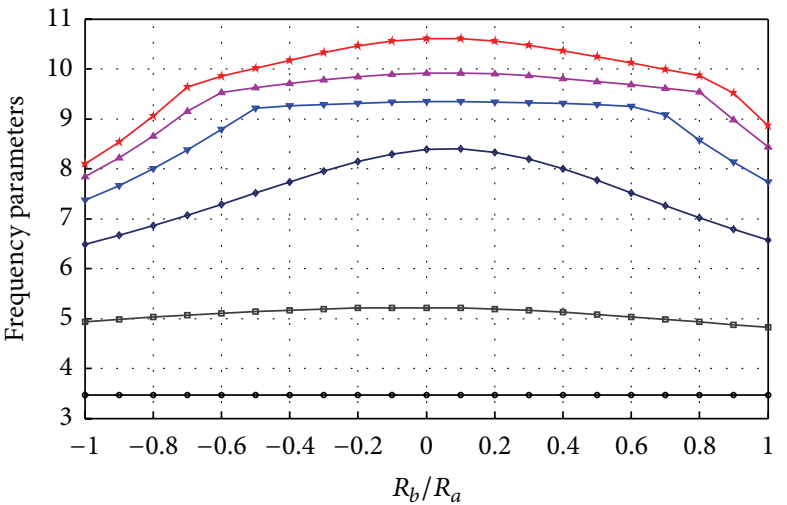

(d)

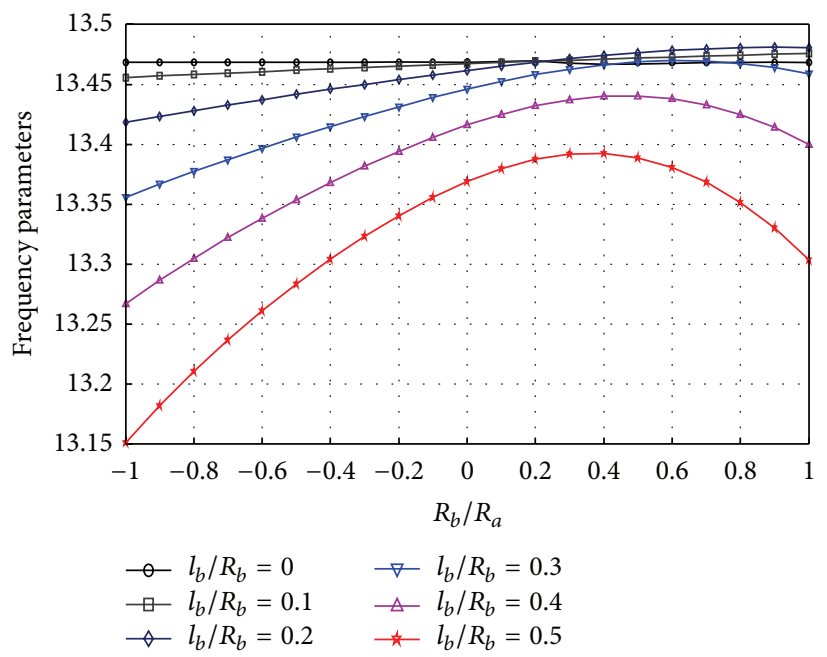

(e)

Figure 5: The first mode frequency as a function of curvature ratio for shells with different boundary conditions: (a) C-C-C-C, (b) C-C-C-F, (c) C-F-C-F, (d) C-F-F-F, and (e) F-F-F-F.

the first frequency parameter of a fully clamped shell with $l_{b} / R_{b}=0.5$ is shown in Figure 6, as the curvature ratio $R_{b} / R_{a}$ is varied from -0.3 to 0.1 . The first mode frequency of the shell gets its minimal (minimum value of the discrete data) when the curvature ratio $R_{b} / R_{a}$ is equal to -0.12 , and the frequency increases with either increasing or decreasing the $x$-direction curvature. The changes in $K_{1} / M_{1}$ and $\partial K_{1} / \partial M_{1}$ of this shell are shown in Figure 7. It can be seen that these two curves have an intersection point when curvature ratio $R_{b} / R_{a}$ is approximately equal to -0.12 . The error is caused by numerical computation.

The second example is one case in Figure 5(e). The change in the first frequency parameter of an F-F-F-F shell with $l_{b} / R_{b}=0.5$ is shown in Figure 8 , as the curvature ratio $R_{b} / R_{a}$ 
TABLE 6: The first frequency parameters of C-C-C-C shallow shells.

\begin{tabular}{|c|c|c|c|c|c|c|}
\hline \multirow{2}{*}{$R_{b} / R_{a}$} & \multicolumn{6}{|c|}{$l_{b} / R_{b}$} \\
\hline & 0 & 0.1 & 0.2 & 0.3 & 0.4 & 0.5 \\
\hline \multirow{2}{*}{-1.0} & & 50.707 & 79.487 & 110.59 & 135.19 & 155.65 \\
\hline & & $(50.750)$ & & (110.80) & & (157.35) \\
\hline-0.9 & & 49.523 & 76.526 & 106.07 & 127.62 & 147.57 \\
\hline-0.8 & & 48.480 & 73.848 & 101.82 & 120.15 & 138.48 \\
\hline-0.7 & & 47.589 & 71.504 & 97.941 & 113.01 & 129.39 \\
\hline-0.6 & & 46.862 & 69.540 & 93.579 & 106.44 & 120.72 \\
\hline \multirow{2}{*}{-0.5} & & 46.305 & 67.999 & 89.835 & 100.65 & 112.89 \\
\hline & & $(46.335)$ & & $(90.225)$ & & (113.65) \\
\hline-0.4 & & 45.926 & 66.921 & 86.814 & 95.871 & 106.27 \\
\hline-0.3 & & 45.730 & 66.332 & 84.612 & 92.317 & 101.26 \\
\hline-0.2 & & 45.719 & 66.250 & 83.309 & 90.176 & 98.185 \\
\hline-0.1 & & 45.894 & 66.678 & 82.958 & 89.578 & 97.291 \\
\hline \multirow{2}{*}{0} & 35.985 & 46.253 & 67.607 & 83.577 & 90.571 & 98.675 \\
\hline & $\left(35.985^{\mathrm{a}}\right)$ & $(46.281)$ & & (83.923) & & (99.263) \\
\hline 0.1 & & 46.791 & 69.014 & 85.151 & 93.116 & 102.27 \\
\hline 0.2 & & 47.502 & 70.867 & 87.629 & 97.095 & 107.85 \\
\hline 0.3 & & 48.377 & 73.128 & 90.937 & 102.34 & 115.14 \\
\hline 0.4 & & 49.408 & 75.751 & 94.986 & 108.66 & 123.82 \\
\hline \multirow{2}{*}{0.5} & & 50.583 & 78.693 & 99.680 & 115.87 & 133.60 \\
\hline & & $(50.618)$ & & $(100.00)$ & & (134.13) \\
\hline 0.6 & & 51.892 & 81.906 & 104.93 & 123.80 & 144.22 \\
\hline 0.7 & & 53.323 & 85.346 & 110.64 & 132.30 & 155.48 \\
\hline 0.8 & & 54.867 & 88.969 & 116.74 & 141.23 & 167.19 \\
\hline 0.9 & & 56.511 & 92.732 & 123.15 & 150.48 & 179.18 \\
\hline \multirow{2}{*}{1.0} & & 58.247 & 96.593 & 129.81 & 159.95 & 191.28 \\
\hline & & $(58.297)$ & & $(130.16)$ & & (191.99) \\
\hline
\end{tabular}

${ }^{\mathrm{a}}$ Results from [14].

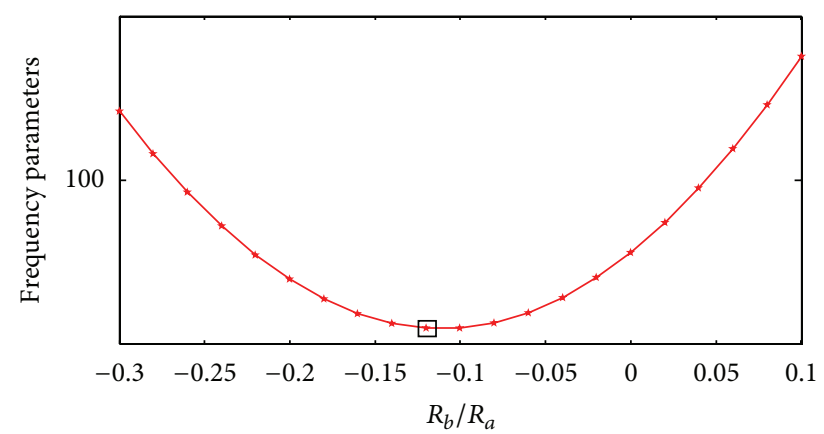

$\square$ Minimum of the discrete data

FIGURE 6: The first mode frequency as a function of curvature ratio for a C-C-C-C shell.

is varied from 0.3 to 0.5 . The first mode frequency of the shell gets its maximal when the curvature ratio $R_{b} / R_{a}$ is equal to 0.36 , and the frequency decreases with either increasing or decreasing the $x$-direction curvature. The $K_{1} / M_{1}$ and $\partial K_{1} / \partial M_{1}$ of this shell as functions of curvature ratio are shown in Figure 9. The value of horizontal ordinate for the
TABLE 7: The first frequency parameters of C-C-C-F shallow shells.

\begin{tabular}{|c|c|c|c|c|c|c|}
\hline \multirow{2}{*}{$R_{b} / R_{a}$} & \multicolumn{6}{|c|}{$l_{b} / R_{b}$} \\
\hline & 0 & 0.1 & 0.2 & 0.3 & 0.4 & 0.5 \\
\hline-1.0 & & 38.344 & 63.123 & 84.048 & 94.427 & 105.48 \\
\hline-0.9 & & 36.441 & 58.579 & 80.959 & 92.572 & 102.83 \\
\hline-0.8 & & 34.643 & 54.101 & 74.174 & 90.733 & 100.16 \\
\hline-0.7 & & 32.971 & 49.744 & 67.323 & 84.768 & 97.506 \\
\hline-0.6 & & 31.446 & 45.573 & 60.539 & 75.735 & 90.829 \\
\hline-0.5 & & 30.093 & 41.670 & 53.971 & 66.684 & 79.600 \\
\hline-0.4 & & 28.937 & 38.139 & 47.805 & 57.919 & 68.363 \\
\hline-0.3 & & 28.005 & 35.111 & 42.294 & 49.825 & 57.684 \\
\hline-0.2 & & 27.320 & 32.739 & 37.783 & 42.954 & 48.332 \\
\hline-0.1 & & 26.901 & 31.180 & 34.701 & 38.086 & 41.478 \\
\hline 0 & 23.931 & 26.762 & 30.563 & 33.463 & 36.095 & 38.603 \\
\hline 0.1 & & 26.906 & 30.945 & 34.266 & 37.441 & 40.566 \\
\hline 0.2 & & 27.3293 & 32.284 & 36.958 & 41.755 & 46.668 \\
\hline 0.3 & & 28.017 & 34.461 & 41.134 & 48.161 & 55.387 \\
\hline 0.4 & & 28.951 & 37.315 & 46.347 & 55.819 & 65.426 \\
\hline 0.5 & & 30.106 & 40.689 & 52.223 & 64.112 & 75.889 \\
\hline 0.6 & & 31.456 & 44.446 & 58.483 & 72.595 & 86.092 \\
\hline 0.7 & & 32.976 & 48.473 & 64.917 & 80.907 & 88.735 \\
\hline 0.8 & & 34.640 & 52.683 & 71.352 & 83.633 & 90.079 \\
\hline 0.9 & & 36.428 & 57.004 & 77.637 & 84.550 & 91.489 \\
\hline 1.0 & & 38.318 & 61.376 & 78.413 & 85.521 & 92.934 \\
\hline
\end{tabular}

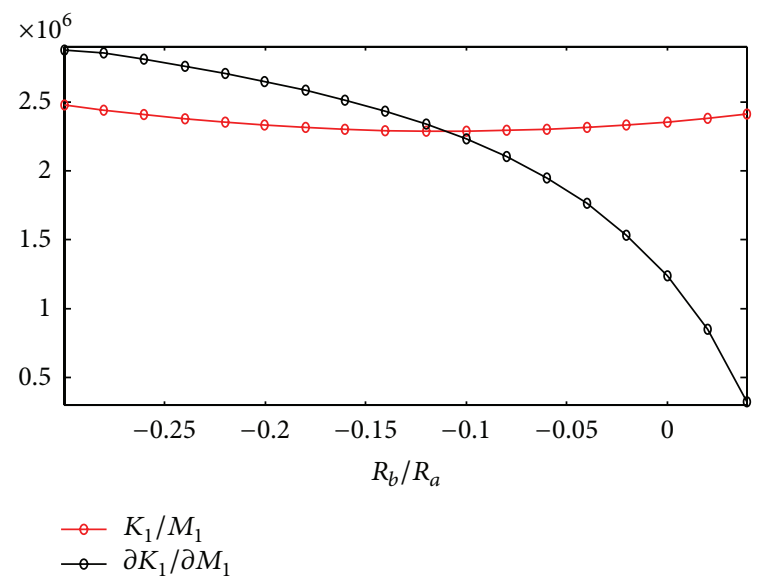

Figure 7: The value of $K_{1} / M_{1}$ and $\partial K_{1} / \partial M_{1}$ as functions of curvature ratio for a $\mathrm{C}-\mathrm{C}-\mathrm{C}-\mathrm{C}$ shell.

intersection point of these two curves is approximately equal to 0.36 .

\section{Conclusions}

The primary purpose of the current work is to assess the effects of curvature on the natural frequencies for the shallow shells with elastic edge restraints. Each of the displacement fields is generally expressed as a modified Fourier series function. The sine function is used to remove the potential discontinuities in related spatial partially differentials. Although 
TABLE 8: The first frequency parameters of C-F-C-F shallow shells.

\begin{tabular}{|c|c|c|c|c|c|c|}
\hline \multirow{2}{*}{$R_{b} / R_{a}$} & \multicolumn{6}{|c|}{$l_{b} / R_{b}$} \\
\hline & 0 & 0.1 & 0.2 & 0.3 & 0.4 & 0.5 \\
\hline \multirow{2}{*}{-1.0} & & 37.096 & 61.134 & 79.890 & 88.221 & 97.623 \\
\hline & & (37.125) & & $(80.303)$ & & (98.611) \\
\hline-0.9 & & 35.166 & 56.586 & 78.103 & 86.839 & 95.828 \\
\hline-0.8 & & 33.343 & 52.092 & 71.450 & 85.579 & 94.183 \\
\hline-0.7 & & 31.647 & 47.709 & 64.679 & 82.005 & 92.660 \\
\hline-0.6 & & 30.103 & 43.503 & 57.930 & 73.143 & 88.445 \\
\hline \multirow{2}{*}{-0.5} & & 28.735 & 39.560 & 51.359 & 64.192 & 77.442 \\
\hline & & $(28.737)$ & & (51.411) & & $(77.473)$ \\
\hline-0.4 & & 27.572 & 35.993 & 45.163 & 55.473 & 66.370 \\
\hline-0.3 & & 26.643 & 32.944 & 39.611 & 47.389 & 55.807 \\
\hline-0.2 & & 25.972 & 30.583 & 35.084 & 40.527 & 46.549 \\
\hline-0.1 & & 25.580 & 29.090 & 32.067 & 35.734 & 39.817 \\
\hline \multirow[t]{2}{*}{0} & 22.176 & 25.481 & 28.607 & 31.029 & 33.973 & 37.170 \\
\hline & $\left(22.171^{\mathrm{a}}\right)$ & (25.463) & & $(30.979)$ & & (36.952) \\
\hline 0.1 & & 25.676 & 29.183 & 32.166 & 35.703 & 39.464 \\
\hline 0.2 & & 26.160 & 30.757 & 35.252 & 40.439 & 45.888 \\
\hline 0.3 & & 26.915 & 33.178 & 39.803 & 47.205 & 54.850 \\
\hline 0.4 & & 27.918 & 36.264 & 45.335 & 55.140 & 65.061 \\
\hline \multirow{2}{*}{0.5} & & 29.141 & 39.848 & 51.472 & 63.644 & 75.653 \\
\hline & & $(29.129)$ & & $(51.478)$ & & (75.723) \\
\hline 0.6 & & 30.557 & 43.789 & 57.945 & 72.297 & 85.965 \\
\hline 0.7 & & 32.138 & 47.977 & 64.559 & 80.756 & 87.010 \\
\hline 0.8 & & 33.858 & 52.329 & 71.154 & 81.636 & 87.562 \\
\hline 0.9 & & 35.695 & 56.778 & 75.744 & 81.814 & 88.035 \\
\hline \multirow{2}{*}{1.0} & & 37.629 & 61.270 & 75.682 & 81.957 & 88.407 \\
\hline & & $(37.636)$ & & $(76.008)$ & & (89.358) \\
\hline
\end{tabular}

${ }^{\mathrm{a}}$ Results from [14].

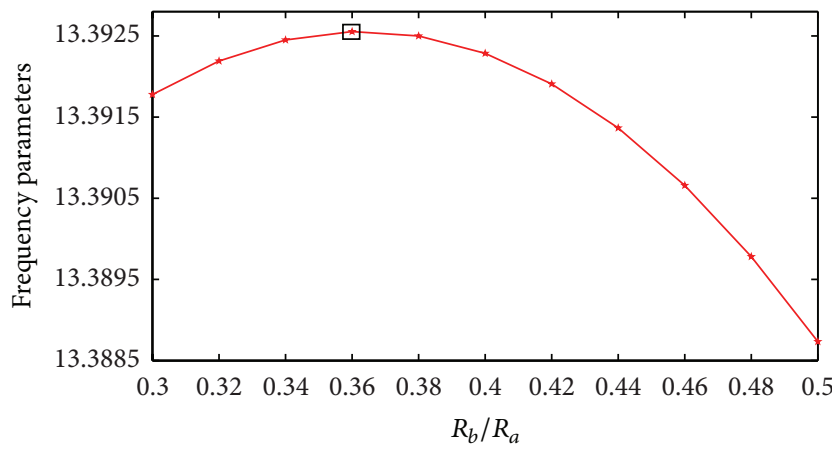

$\square$ Maximum of the discrete data

Figure 8: The first mode frequency as a function of curvature ratio for an F-F-F-F shell.

the current solution is sought in a weak form by using the Rayleigh-Ritz method, it is mathematically equivalent to the strong from through solving the governing equations and the boundary conditions because the displacement functions represented by the series expansions are adequately smooth throughout the entire solution domain. The effectiveness
TABLE 9: The first frequency parameters of C-F-F-F shallow shells.

\begin{tabular}{|c|c|c|c|c|c|c|}
\hline \multirow{2}{*}{$R_{b} / R_{a}$} & \multicolumn{6}{|c|}{$l_{b} / R_{b}$} \\
\hline & 0 & 0.1 & 0.2 & 0.3 & 0.4 & 0.5 \\
\hline \multirow{3}{*}{-1.0} & & 4.9390 & 6.4878 & 7.3699 & 7.8426 & 8.0919 \\
\hline & & $(4.9410)$ & & $(7.4051)$ & & $(8.2255)$ \\
\hline & & [4.9440] & [6.5038] & [7.4128] & & [8.2429] \\
\hline-0.9 & & 4.9825 & 6.6661 & 7.6655 & 8.2239 & 8.5387 \\
\hline-0.8 & & 5.0252 & 6.8587 & 7.9971 & 8.6576 & 9.0487 \\
\hline-0.7 & & 5.0663 & 7.0653 & 8.3697 & 9.1546 & 9.6369 \\
\hline \multirow[t]{2}{*}{-0.6} & & 5.1048 & 7.2840 & 8.7874 & 9.5269 & 9.8504 \\
\hline & & 5.1396 & 7.5104 & 9.2176 & 9.6185 & 10.010 \\
\hline \multirow[t]{2}{*}{-0.5} & & (5.1385) & & $(9.2357)$ & & $(10.056)$ \\
\hline & & [5.1414] & [7.5071] & & & {$[10.062]$} \\
\hline-0.4 & & 5.1694 & 7.7375 & 9.2555 & 9.7052 & 10.170 \\
\hline-0.3 & & 5.1931 & 7.9543 & 9.2880 & 9.7834 & 10.322 \\
\hline-0.2 & & 5.2095 & 8.1458 & 9.3140 & 9.8483 & 10.456 \\
\hline-0.1 & & 5.2176 & 8.2943 & 9.3323 & 9.8949 & 10.556 \\
\hline \multirow{3}{*}{0} & 3.4719 & 5.2167 & 8.3822 & 9.3424 & 9.9193 & 10.608 \\
\hline & $\left(3.4714^{\mathrm{a}}\right)$ & $(5.2146)$ & & $(9.3516)$ & & (10.589) \\
\hline & {$\left[3.4730^{\mathrm{b}}\right]$} & [5.2174] & [8.3683] & & & [10.595] \\
\hline 0.1 & & 5.2066 & 8.3962 & 9.3441 & 9.9203 & 10.606 \\
\hline 0.2 & & 5.1873 & 8.3318 & 9.3379 & 9.8996 & 10.557 \\
\hline 0.3 & & 5.1596 & 8.1954 & 9.3246 & 9.8612 & 10.472 \\
\hline \multirow[t]{2}{*}{0.4} & & 5.1241 & 8.0020 & 9.3052 & 9.8097 & 10.365 \\
\hline & & 5.0823 & 7.7709 & 9.2807 & 9.7488 & 10.246 \\
\hline \multirow[t]{2}{*}{0.5} & & (5.0815) & & $(9.3020)$ & & (10.284) \\
\hline & & [5.0840] & [7.7655] & & & [10.295] \\
\hline 0.6 & & 5.0354 & 7.5207 & 9.2520 & 9.6815 & 10.121 \\
\hline 0.7 & & 4.9848 & 7.2667 & 9.0767 & 9.6096 & 9.9934 \\
\hline 0.8 & & 4.9318 & 7.0193 & 8.5747 & 9.5342 & 9.8641 \\
\hline \multirow[t]{2}{*}{0.9} & & 4.8777 & 6.7852 & 8.1283 & 8.9808 & 9.5183 \\
\hline & & 4.8234 & 6.5675 & 7.7347 & 8.4410 & 8.8618 \\
\hline \multirow[t]{2}{*}{1.0} & & $(4.8259)$ & & (7.7733) & & $(9.0054)$ \\
\hline & & [4.8282] & [6.5854] & [7.7836] & & [9.0327] \\
\hline
\end{tabular}

${ }^{\mathrm{a}}$ Results from [14].

${ }^{\mathrm{b}}$ Results from [18].

of current method is verified through the comparison of numerical results. The first mode frequencies of shallow shells with various $x$-direction and $y$-direction curvature under five kinds of boundary conditions are calculated. The results show that increasing $y$-direction curvature causes a considerable increase in the first mode frequency for the shell at least having one clamped edge while the other edges are free; increasing $y$-direction curvature causes a decrease in the first mode frequency of a completely free shell when $l_{b} / R_{b}$ is greater than 0.2 ; giving significant $x$-direction curvature, either positive or negative, can cause an increase in the first mode frequency for the shell at least having two clamped edges while the other edges are free, which is just the opposite for a cantilever shell; the minimum value of the first mode frequency occurs for a completely clamped shell with negative Gaussian 
TABLE 10: The first frequency parameters of F-F-F-F shallow shells.

\begin{tabular}{|c|c|c|c|c|c|c|}
\hline \multirow{2}{*}{$R_{b} / R_{a}$} & \multicolumn{6}{|c|}{$l_{b} / R_{b}$} \\
\hline & 0 & 0.1 & 0.2 & 0.3 & 0.4 & 0.5 \\
\hline $\begin{array}{l}-1.0 \\
\end{array}$ & & 13.456 & 13.419 & 13.356 & 13.267 & 13.151 \\
\hline-0.9 & & 13.457 & 13.423 & 13.367 & 13.287 & 13.182 \\
\hline-0.8 & & 13.458 & 13.428 & 13.377 & 13.305 & 13.211 \\
\hline-0.7 & & 13.459 & 13.433 & 13.387 & 13.322 & 13.237 \\
\hline-0.6 & & 13.461 & 13.437 & 13.397 & 13.338 & 13.261 \\
\hline-0.5 & & 13.462 & 13.442 & 13.406 & 13.354 & 13.283 \\
\hline-0.4 & & 13.463 & 13.446 & 13.415 & 13.368 & 13.304 \\
\hline-0.3 & & 13.464 & 13.450 & 13.423 & 13.382 & 13.323 \\
\hline-0.2 & & 13.465 & 13.454 & 13.431 & 13.394 & 13.341 \\
\hline-0.1 & & 13.466 & 13.458 & 13.439 & 13.406 & 13.356 \\
\hline 0 & 13.468 & 13.467 & 13.462 & 13.446 & 13.416 & 13.369 \\
\hline 0.1 & & 13.468 & 13.465 & 13.453 & 13.425 & 13.380 \\
\hline 0.2 & & 13.469 & 13.468 & 13.458 & 13.432 & 13.388 \\
\hline 0.3 & & 13.470 & 13.471 & 13.463 & 13.437 & 13.392 \\
\hline 0.4 & & 13.471 & 13.474 & 13.466 & 13.440 & 13.392 \\
\hline 0.5 & & 13.472 & 13.476 & 13.469 & 13.440 & 13.389 \\
\hline 0.6 & & 13.473 & 13.478 & 13.470 & 13.438 & 13.381 \\
\hline 0.7 & & 13.474 & 13.480 & 13.469 & 13.433 & 13.369 \\
\hline 0.8 & & 13.474 & 13.481 & 13.467 & 13.425 & 13.352 \\
\hline 0.9 & & 13.475 & 13.481 & 13.464 & 13.414 & 13.330 \\
\hline 1.0 & & 13.476 & 13.481 & 13.459 & 13.400 & 13.304 \\
\hline
\end{tabular}

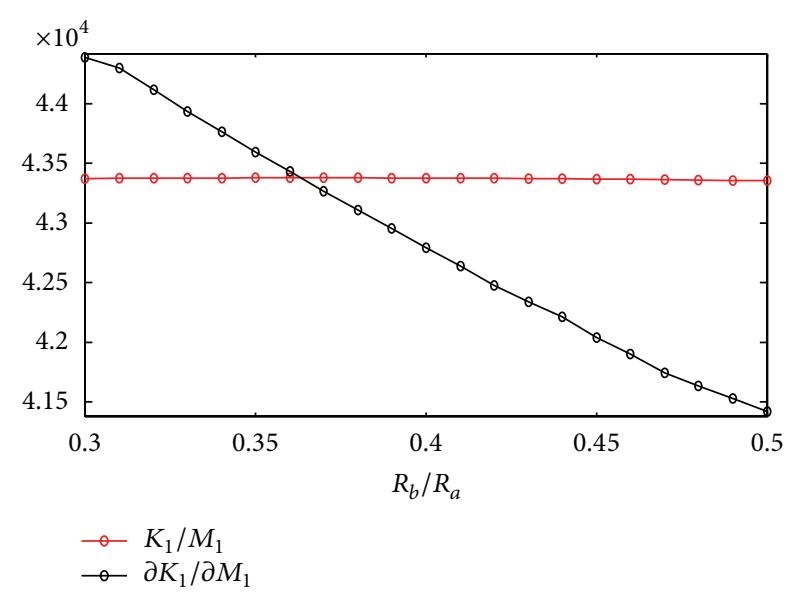

Figure 9: The value of $K_{1} / M_{1}$ and $\partial K_{1} / \partial M_{1}$ as functions of curvature ratio for an F-F-F-F shell.

curvature and the maximal value of the first mode frequency occurs of a completely free shell with positive Gaussian curvature.

\section{Appendix}

\section{Matrix Definitions}

The stiffness matrix in (15) can be expressed as

$$
\mathbf{K}=\mathbf{K}_{\mathrm{be}}+\mathbf{K}_{\mathrm{in}}+\mathbf{K}_{\mathrm{co}}+\mathbf{K}_{\mathrm{sp}} \text {, }
$$

where $\mathbf{K}_{\mathrm{be}}, \mathbf{K}_{\mathrm{in}}, \mathbf{K}_{\mathrm{co}}$, and $\mathbf{K}_{\mathrm{sp}}$ are stiffness matrix of the shell corresponding to the bending energy, the membrane energy, the coupling energy between out-of-plane and inplane motions, and potential energy stored in the boundary restraining springs

$$
\begin{gathered}
\mathbf{K}_{\mathrm{be}}=\left[\begin{array}{ccc}
\mathbf{0} & \mathbf{0} & \mathbf{0} \\
\vdots & \mathbf{0} & \mathbf{0} \\
\mathbf{S} & \cdots & \mathbf{K}_{\mathrm{be}}^{w, w}
\end{array}\right], \\
\mathbf{K}_{\mathrm{in}}=\left[\begin{array}{ccc}
\mathbf{K}_{\mathrm{in}}^{u, u} & \mathbf{K}_{\mathrm{in}}^{u, v} & \mathbf{K}_{\mathrm{in}}^{u, w} \\
\vdots & \mathbf{K}_{\mathrm{in}}^{v, v} & \mathbf{K}_{\mathrm{in}}^{v, w} \\
\mathbf{S} & \cdots & \mathbf{K}_{\mathrm{in}}^{w, w}
\end{array}\right], \\
\mathbf{K}_{\mathrm{co}}=\left[\begin{array}{ccc}
\mathbf{0} & \mathbf{0} & \mathbf{K}_{\mathrm{co}}^{u, w} \\
\vdots & \mathbf{0} & \mathbf{K}_{\mathrm{co}}^{v, w} \\
\mathbf{S} & \cdots & \mathbf{K}_{\mathrm{in}}^{w, w}
\end{array}\right], \\
\mathbf{K}_{\mathrm{sp}}=\left[\begin{array}{ccc}
\mathbf{K}_{\mathrm{sp}}^{u, u} & \mathbf{0} & \mathbf{0} \\
\vdots & \mathbf{K}_{\mathrm{sp}}^{v, v} & \mathbf{0} \\
\mathbf{S} & \cdots & \mathbf{K}_{\mathrm{sp}}^{w, w}
\end{array}\right] .
\end{gathered}
$$

The shell mass matrix in (15) is given by

$$
\mathbf{M}=\left[\begin{array}{ccc}
\mathbf{M}^{u} & \mathbf{0} & \mathbf{0} \\
\vdots & \mathbf{M}^{v} & \mathbf{0} \\
\mathbf{S} & \cdots & \mathbf{M}^{w}
\end{array}\right]
$$

\section{Nomenclature}

$K_{x_{0}}, K_{x_{a}}\left(K_{y_{0}}, K_{y_{b}}\right)$ : Stiffnesses for rotational springs, respectively, at $x=0$ and $a(y=0$ and b)

$k_{x_{0}}^{f}, k_{x_{a}}^{f}\left(k_{y_{0}}^{f}, k_{y_{b}}^{f}\right)$ Stiffnesses for flexural springs, respectively, at $x=0$ and $a(y=0$ and b)

$k_{x_{0}}^{l}, k_{x_{a}}^{l}\left(k_{y_{0}}^{l}, k_{y_{b}}^{l}\right): \quad$ Stiffnesses for longitudinal springs, respectively, at $x=0$ and $a$ ( $y=0$ and b)

$k_{x_{0}}^{t}, k_{x_{a}}^{t}\left(k_{y_{0}}^{t}, k_{y_{b}}^{t}\right): \quad$ Stiffnesses for tangential springs, respectively, at $x=0$ and $a(y=0$ and b)

$\omega: \quad$ Frequency in radian.

\section{Conflict of Interests}

The authors declare that there is no conflict of interests regarding the publication of this paper.

\section{Acknowledgment}

The work was supported by the National Natural Science Foundation of China (Grant no. 51375103). 


\section{References}

[1] A. W. Leissa, "Vibration of shells," NASA SP-288, Government Printing Office, Washington, DC, USA, 1973.

[2] M. S. Qatu, "Review of shallow shell vibration research," The Shock and Vibration Digest, vol. 24, pp. 3-15, 1992.

[3] M. S. Qatu, "Recent research advances in the dynamic behavior of shells: 1989-2000, Part 2: homogeneous shells," Applied Mechanics Reviews, vol. 55, no. 5, pp. 415-434, 2002.

[4] K. M. Liew, C. W. Lim, and S. Kitipornchai, "Vibration of shallow shells: a review with bibliography," Applied Mechanics Reviews, vol. 50, no. 8, pp. 431-444, 1997.

[5] P. J. Palmer, "The natural frequency of vibration of curved rectangular plates," Aeronautical Quarterly, vol. 5, pp. 101-110, 1954.

[6] M. D. Olson and G. M. Lindberg, "Vibration analysis of cantilevered curved plates using a new cylindrical shell finite element," in Proceedings of the 2nd Conference on Matrix Method in Structural Mechanics, AFFDL-TR-69-150, pp. 247-270, WrightPatterson Air Force Base, Ohio, USA, 1969.

[7] M. D. Olson and G. M. Lindberg, "Dynamic analysis of shallow shells with a doubly-curved triangular finite element," Journal of Sound and Vibration, vol. 19, no. 3, pp. 299-310, 1971.

[8] G. R. Cowper, G. M. Lindberg, and M. D. Olson, "A shallow shell finite element of triangular shape," International Journal of Solids and Structures, vol. 6, no. 8, pp. 1133-1156, 1970.

[9] J. M. D. Nath, Dynamics of rectangular curved plates [Ph.D. thesis], University of Southampton, 1969.

[10] M. Petyt and J. M. D. Nath, "Vibration analysis of singly curved rectangular plates," Journal of Sound and Vibration, vol. 13, no. 4, pp. 485-497, 1970.

[11] M. Petyt, "Vibration of curved plates," Journal of Sound and Vibration, vol. 15, no. 3, pp. 381-395, 1971.

[12] I. Elishakoff and F. Wiener, "Vibration of an open shallow cylindrical shell," Journal of Sound and Vibration, vol. 44, no. 3, pp. 379-392, 1976.

[13] K. P. Walker, "Vibrations of cambered helicoidal fan blades," Journal of Sound and Vibration, vol. 59, no. 1, pp. 35-57, 1978.

[14] K. M. Liew and C. W. Lim, "Vibration of doubly-curved shallow shells," Acta Mechanica, vol. 114, pp. 95-119, 1996.

[15] A. W. Leissa and Y. Narita, "Vibrations of completely free shallow shells of rectangular planform," Journal of Sound and Vibration, vol. 96, no. 2, pp. 207-218, 1984.

[16] M. S. Qatu and E. Asadi, "Vibration of doubly curved shallow shells with arbitrary boundaries," Applied Acoustics, vol. 73, no. 1, pp. 21-27, 2012.

[17] C. W. Lim and K. M. Liew, "pb-2 Ritz formulation for flexural vibration of shallow cylindrical shells of rectangular planform," Journal of Sound and Vibration, vol. 173, no. 3, pp. 343-375, 1994.

[18] A. W. Leissa, J. K. Lee, and A. J. Wang, "Vibrations of cantilevered doubly-curved shallow shells," International Journal of Solids and Structures, vol. 19, no. 5, pp. 411-424, 1983.

[19] A. W. Leissa, J. K. Lee, and A. J. Wang, "Vibrations of cantilevered shallow cylindrical shells of rectangular planform," Journal of Sound and Vibration, vol. 78, no. 3, pp. 311-328, 1981.

[20] Y. Narita and A. W. Leissa, "Vibrations of corner point supported shallow shells of rectangular planform," Earthquake Engineering \& Structural Dynamics, vol. 12, no. 5, pp. 651-661, 1984.

[21] J. K. Lee, A. W. Leissa, and A. J. Wang, "Vibrations of cantilevered circular cylindrical shells: shallow versus deep shell theory," International Journal of Mechanical Sciences, vol. 25, no. 5, pp. 361-383, 1983.

[22] M. S. Qatu and A. W. Leissa, "Vibration of shallow shells with two adjacent edges clamped and the other free," Mechanics of Structures and Machines, vol. 21, pp. 285-301, 1993.

[23] M. S. Qatu and A. W. Leissa, "Effects of edge constraints upon shallow shell frequencies," Thin-Walled Structures, vol. 14, no. 5, pp. 347-379, 1992.

[24] M. S. Qatu, "Effect of inplane edge constraints on natural frequencies of simply supported doubly curved shallow shells," Thin-Walled Structures, vol. 49, no. 7, pp. 797-803, 2011.

[25] K. M. Liew and C. W. Lim, "Vibration of perforated doublycurved shallow shells with rounded corners," International Journal of Solids and Structures, vol. 31, no. 11, pp. 1519-1536, 1994.

[26] K. M. Liew and C. W. Lim, "Vibratory characteristics of cantilevered rectangular shallow shells of variable thickness," AIAA journal, vol. 32, no. 2, pp. 387-396, 1994.

[27] K. M. Liew and C. W. Lim, "Vibration behavior of doubly curved shallow shells of curvilinear planform," Journal of Engineering Mechanics, vol. 121, pp. 1227-1283, 1995.

[28] K. M. Liew, S. Kitipornchai, and C. W. Lim, "Comparative accuracy of shallow and deep shell theories for vibration of cylindrical shells," Journal of Vibration and Control, vol. 3, no. 1, pp. 119-143, 1997.

[29] Y. K. Cheung, W. Y. Li, and L. G. Tham, "Free vibration analysis of singly curved shell by spline finite strip method," Journal of Sound and Vibration, vol. 128, no. 3, pp. 411-422, 1989.

[30] S. T. Choi and Y. T. Chou, "Vibration analysis of non-circular curved panels by the differential quadrature method," Journal of Sound and Vibration, vol. 259, no. 3, pp. 525-539, 2003.

[31] V. Z. Vlasov, "General theory of shells and its application in engineering," NASA TTF-99, Office of Technical Services, Washington, DC, USA, 1964.

[32] A. W. Leissa and A. S. Kadi, "Curvature effects on shallow shell vibrations," Journal of Sound and Vibration, vol. 16, no. 2, pp. 173-187, 1971.

[33] X. Zhang and W. L. Li, "Vibrations of rectangular plates with arbitrary non-uniform elastic edge restraints," Journal of Sound and Vibration, vol. 326, no. 1-2, pp. 221-234, 2009.

[34] S. L. Jiang, W. L. Li, T. J. Yang, and J. T. Du, "Free vibration analysis of doubly curved shallow shells reinforced by any number of beams with arbitrary lengths," Journal of Vibration and Control, 2014.

[35] Substrctured, Meshless and Parametric Modeling of Vibroacoustic Systems, Phase I SBIR Final Report, Comet Technology Corporation, 2013. 

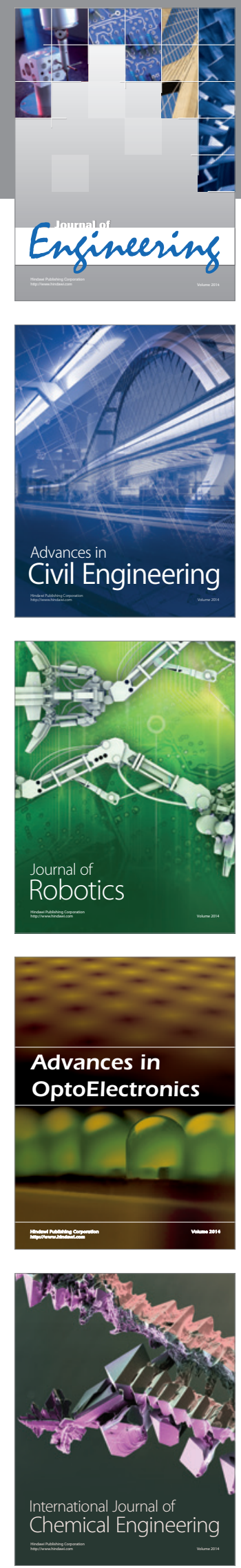

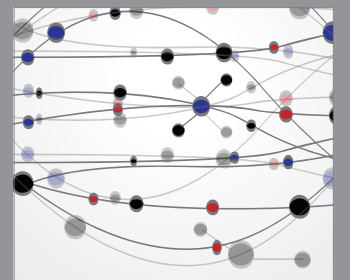

The Scientific World Journal
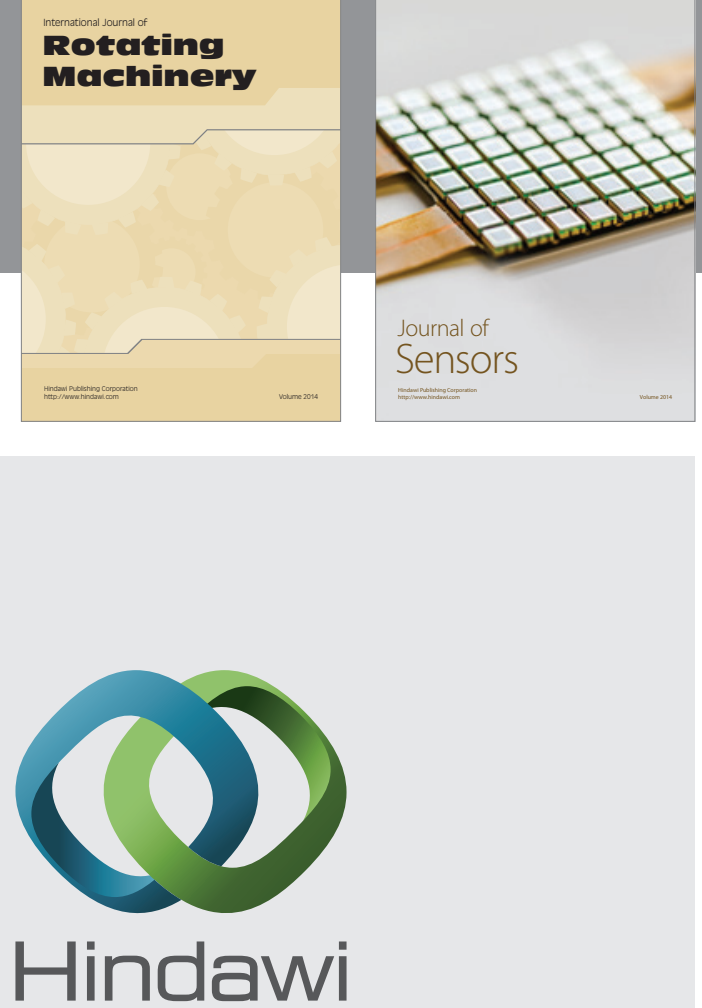

Submit your manuscripts at http://www.hindawi.com
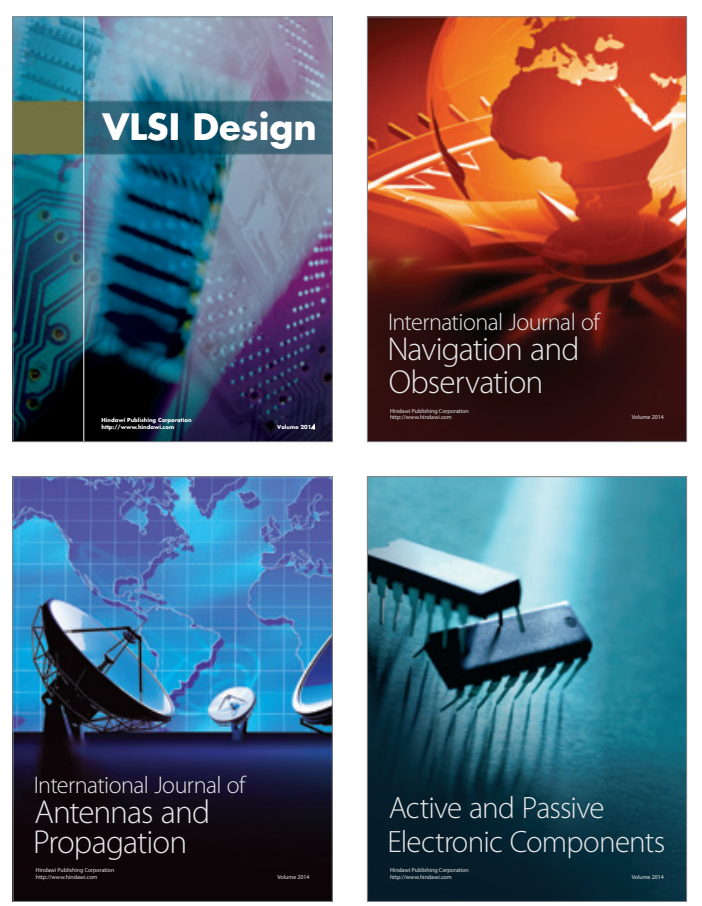
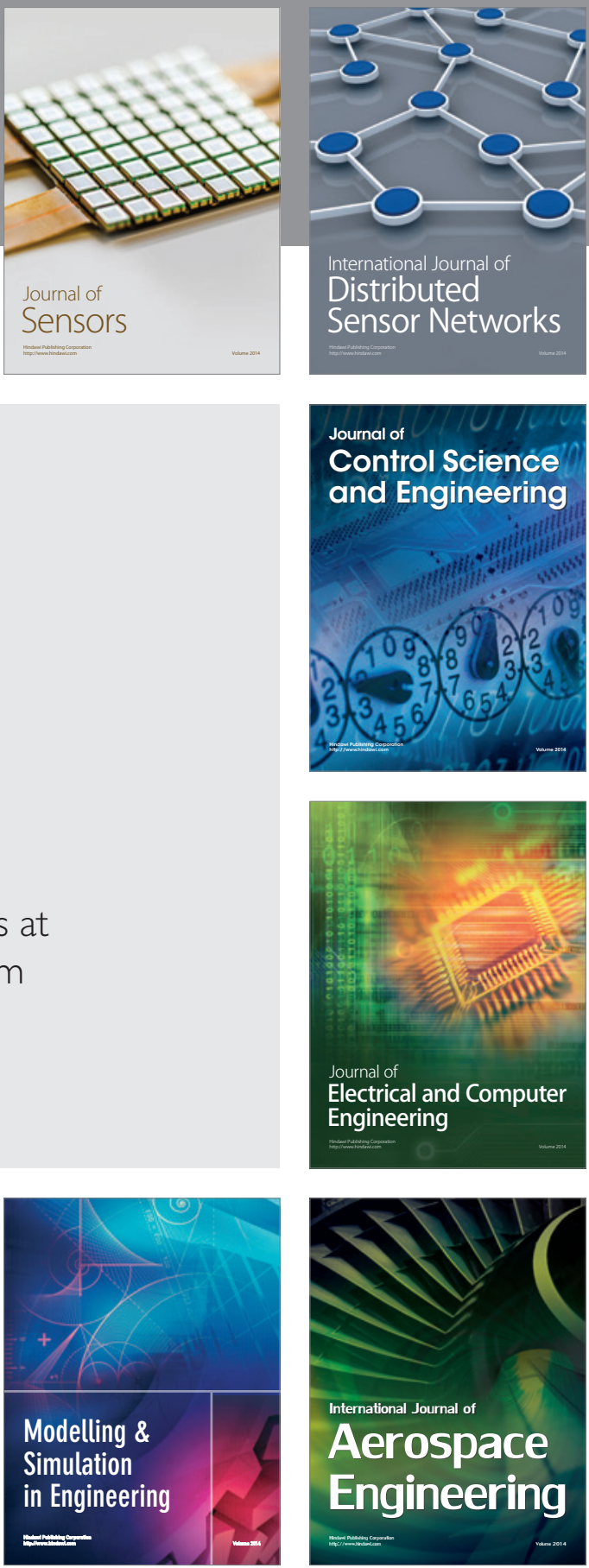

Journal of

Control Science

and Engineering
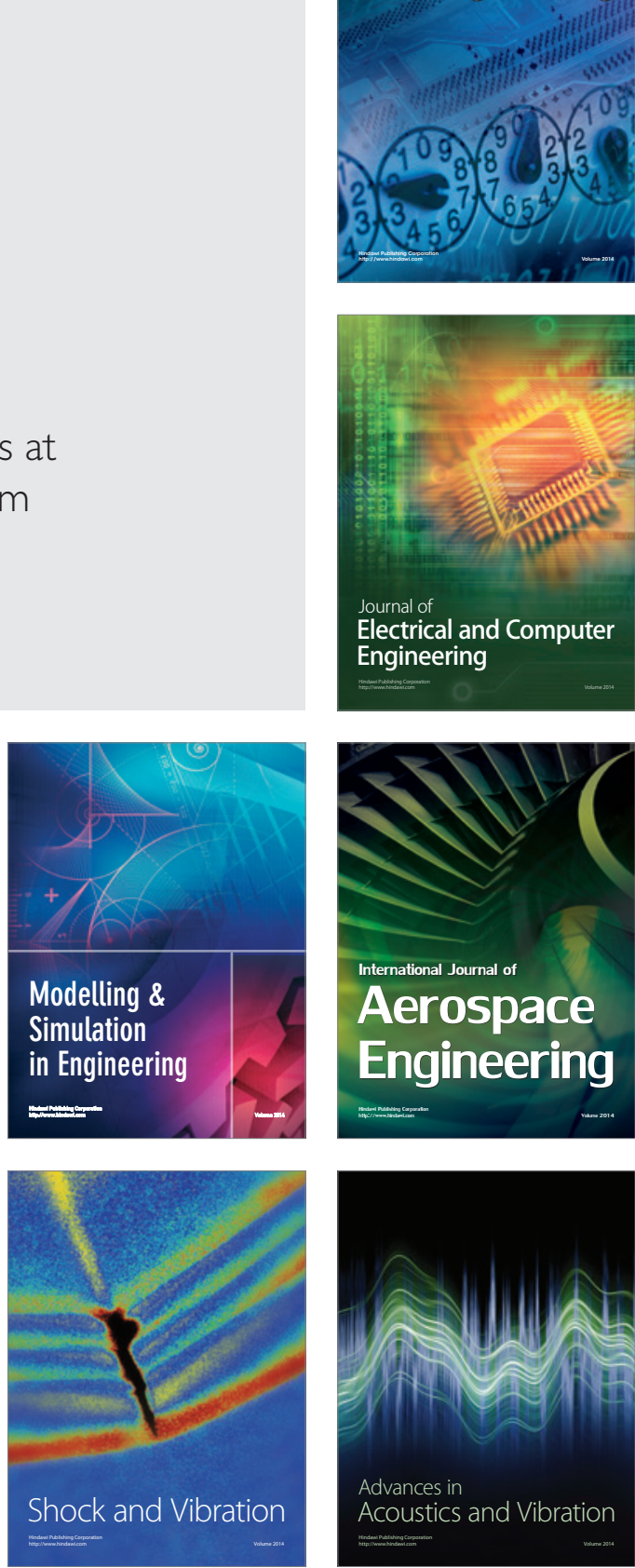